NBER WORKING PAPER SERIES

\title{
SHORT-RUN PAIN, LONG-RUN GAIN? RECESSIONS AND TECHNOLOGICAL TRANSFORMATION
}

\author{
Alexandr Kopytov \\ Nikolai Roussanov \\ Mathieu Taschereau-Dumouchel \\ Working Paper 24373 \\ http://www.nber.org/papers/w24373 \\ NATIONAL BUREAU OF ECONOMIC RESEARCH \\ 1050 Massachusetts Avenue \\ Cambridge, MA 02138 \\ March 2018
}

We thank Henry Siu (discussant), Sevin Yeltekin (editor), seminar participants at Columbia, Wharton, and conference participants at the Carnegie-Rochester-NYU Conference on Public Policy, for which this paper was prepared. The views expressed herein are those of the authors and do not necessarily reflect the views of the National Bureau of Economic Research.

NBER working papers are circulated for discussion and comment purposes. They have not been peer-reviewed or been subject to the review by the NBER Board of Directors that accompanies official NBER publications.

(C) 2018 by Alexandr Kopytov, Nikolai Roussanov, and Mathieu Taschereau-Dumouchel. All rights reserved. Short sections of text, not to exceed two paragraphs, may be quoted without explicit permission provided that full credit, including $(\mathbb{C}$ notice, is given to the source. 
Short-Run Pain, Long-Run Gain? Recessions and Technological Transformation

Alexandr Kopytov, Nikolai Roussanov, and Mathieu Taschereau-Dumouchel

NBER Working Paper No. 24373

March 2018

JEL No. E24,E25,E3

\begin{abstract}
$\underline{\text { ABSTRACT }}$
Recent empirical evidence suggests that job polarization associated with skill-biased technological change accelerated during the Great Recession. We use a standard neoclassical growth framework to analyze how business cycle fluctuations interact with the long-run transition towards a skill-intensive technology. In the model, since adopting the new technology disrupts production, firms prefer to do so in recessions, when profits are low. Similarly, workers also tend to learn new skills during downturns. As a result, recessions are deeper during periods of technological transition, but they also speed up adoption of the new technology. We document evidence for these mechanisms in the data. Our calibrated model is able to match both the longrun downward trend in routine employment and the dramatic impact of the Great Recession. We also show that even in the absence of the Great Recession the routine employment share would have reached the observed level by the year 2012 .

Alexandr Kopytov

University of Pennsylvania

The Wharton School, Finance Department

2400 Steinberg-Dietrich Hall

3620 Locust Walk

Philadelphia, PA 19104-6367

akopytov@wharton.upenn.edu

Nikolai Roussanov

University of Pennsylvania

The Wharton School, Finance Department

2400 Steinberg-Dietrich Hall

3620 Locust Walk

Philadelphia, PA 19104-6367

and NBER

nroussan@wharton.upenn.edu

Mathieu Taschereau-Dumouchel

Cornell University

Department of Economics

Uris Hall, Ithaca, NY 14853

mathtd@gmail.com
\end{abstract}




\section{Introduction}

In recent decades, rapid advances in information technology, electronics and robotics have made many jobs associated with relatively simple and repetitive tasks obsolete, as they can now be easily performed by machines. While these routine jobs have been disappearing, employment in nonroutine cognitive occupations (e.g., programmers or financial analysts) and non-routine manual jobs (mainly in low-skill services), has been increasing. Both of these types of occupations are associated with tasks that have proved harder to automate, at least thus far. ${ }^{1}$

In a recent contribution, Jaimovich and Siu (2015) (JS hereafter) have shown that this job polarization process accelerates during recessions. Over the last thirty years, employment in routine occupations experienced significant drops during economic downturns and, unlike for other types of jobs, these drops were not followed by recoveries once the recessions ended. Strikingly, $88 \%$ of job losses in routine occupations since the mid-1980s happened during the three downturns that occurred over this span of time. In contrast, non-routine jobs experienced only small declines during these recessions, and rapidly recovered afterwards. Importantly, these patterns began during the mid-1980s, when the pace of innovation in automation technologies accelerated (e.g., see Eden and Gaggl, 2016). In prior decades, routine employment bounced back quickly as economy recovered.

We build a quantitative model to better understand these patterns, and to evaluate their importance for macroeconomic fluctuations and technology adoption. In the model, consumption goods are produced using manual services and intermediates. Guided by the data, we assume that the manual services employs low-skill workers to perform non-routine manual tasks. Production of intermediates, in contrast, is more complex and requires a combination of non-routine cognitive tasks, performed by high-skill workers, and routine tasks, performed by low-skill workers, similarly to Autor and Dorn (2013). While only one technology is available to produce manual services, firms can choose either an "old" or a "new" technology to produce intermediates. The new technology is more skill-intensive than the old one, and it becomes better over time due to continued improvements in information technologies and automation (Autor, Levy, and Murnane, 2003). As a result, firms progressively switch from the old to the new technology, and non-routine cognitive employment goes up as a result. Moreover, since manual services and intermediates are complements, non-routine manual employment also increases. The slow improvement in the pro-

\footnotetext{
${ }^{1}$ For more on job polarization see Acemoglu (1999), Autor, Levy, and Murnane (2003), Goos and Manning (2007), Goos, Manning, and Salomons (2014) among others.
} 
ductivity of the new technology therefore generates patterns of job polarization similar to those visible in the data.

Adopting the new technology is costly, both in terms of factors of production that must be used to reorganize the firm, but also in terms of the profits that are lost during the reorganization. As a result, firms in our model prefer to adopt the new technology during recessions, when factors of production are cheap and the loss in foregone profits is minimized. Recessions are also periods of skill acquisition by the workers. Since wages are depressed, low-skill workers take advantage of the low opportunity costs to acquire the new skills which will be in high demand once the firms begin using the new technology towards the end of the recession. Together, the adoption of new technology by firms and the acquisition of skills by workers take resources away from production during downturns and, as a result, amplify the effect of negative business cycle shocks. At the same time, this short-run pain creates long-lasting value in the form of a better production technology and a higher skill level.

The patterns of technology adoption and skill acquisition generated by the model have support in the data. The evidence is particularly telling during the Great Recession. Indeed, while the recession is accompanied by a decline in routine employment, post-secondary education enrollment increases markedly over the same period. At the same time, while aggregate investment fell massively, investment in new equipment and software technology was mostly unaffected or slowed down only slightly. International shipment of industrial robots increased sharply as the recession ended.

We calibrate the economy to match standard real business cycle moments and the overall increase in the employment share of non-routine cognitive workers. Importantly, for a reasonable level of complementarity between intermediates and manual services, the model is able to explain the recent growth in the employment share of non-routine manual labor, as well as the decline in routine manual jobs. We demonstrate that by feeding into our model a large negative TFP shock that corresponds to the Great Recession in both its magnitude and its timing (relative to the process of technological transition), we can largely account for the sharp drop in the share of routine workers in the labor force that occurred between 2008 and 2010. We also show that even in the counterfactual scenario in which the economy does not suffer the Great Recession the smooth process of technological transition still delivers the employment share of routine manual workers that is observed empirically in 2012. Thus, while the Great Recession may have accelerated the process of job polarization, it does not seem to have contributed substantially to its long-term trend. 


\section{Literature Review}

We model technological progress as involving a change in the production function, reminiscent of the general purpose technology literature (e.g., Helpman, 1998). We also assume that the new technology is relatively more high-skill-intensive, similar to Heckman, Lochner, and Taber (1998) and Goldin and Katz (1998). Relatedly, Buera, Kaboski, and Rogerson (2015) also hypothesize that the share of high-skill labor in production function has increased as a result of the recent technological change. An alternative approach would be to use the notion of capital-skill complementarity, as proposed by Griliches (1969) and Krusell, Ohanian, Rios-Rull, and Violante (2000). There, technological progress makes capital equipment more productive and cheaper, causing increase in demand for the high skill.

In our model, technology adoption requires both time and resources. In this regard, it is similar to Jovanovic and Macdonald (1994), Andolfatto and MacDonald (1998) and, especially, to Greenwood and Yorukoglu (1997) who assume that high-skill labor is essential to adopt new technologies.

In a "pit stop" model of technology adoption, which is reminiscent of the Schumpeterian view of recessions, periods of depressed economic activity are used by firms to reorganize production or invest in organizational capital (e.g., Hall, 1991 Cooper and Haltiwanger, 1993, Aghion and SaintPaul, 1998, and Caballero and Engel, 1999). ${ }^{2}$ Recently, these ideas have been brought to explain anemic employment recoveries following the three latest recessions (van Rens, 2004, Koenders and Rogerson, 2005, and Berger, 2012).

We model training in the spirit of real business cycle models augmented with human capital accumulation as in Perli and Sakellaris (1998) and DeJong and Ingram (2001). As a result, in our model investment in human capital also increases during recessions. Counter-cyclical investment in education is a well-established fact in the empirical literature (see, among many others, Dellas and Sakellaris, 2003, Charles, Hurst, and Notowidigdo, 2015, and Barr and Turner, 2015).

The remainder of the paper is organized as follows. Section 2 discusses recent empirical evidence on the interaction between routine-biased technological change and recessions. Section 3 describes the model. We calibrate the model in Section 4. Section 5 contains quantitative exercises. Section 6 concludes.

\footnotetext{
${ }^{2}$ Schumpeter (1934) considers recessions as "industrial mutation that incessantly revolutionizes the economic structure from within, incessantly destroying the old one, incessantly creating a new one". Caballero and Hammour (1994) study how the process of creative destruction interacts with business cycles.
} 


\section{Empirical evidence}

In this section, we discuss empirical evidence about interaction between recent downturns and the speed of job polarization. We then show that some forms of investment in skill-complementary capital (e.g., software and information processing equipment), are only mildly pro-cyclical, in contrast with very pro-cyclical investment in structures. We use this evidence to help motivate our model, in which adoption of a new skill-intensive technology requires reorganization of the firm that disrupts production and is therefore more attractive during periods of low opportunity costs. At the same time, workers use recessions to invest in their human capital in order to satisfy the increasing demand for skill, which results in accelerated job polarization.

A large empirical literature documents that job polarization, induced by routine-biased technological change, was accelerated by recent recessions. Hershbein and Kahn (2016) show that demand for high-skill workers rises in metropolitan statistical areas with lower employment growth. This "upskilling" effect is long lasting and does not disappear even when then labor market recovers. Moreover, firms that upskill more actively also invest more. Anghel, De la Rica, and Lacuesta (2014) document that the Great Recession sped up job polarization in Spain. Zhang (2015) finds that during crises firms intensive in routine labor reduce routine employment and invest more in machines. Using a panel of Spanish manufacturing firms, Aguirregabiria and Alonso-Borrego (2001) show that firms' decisions to reorganize production is counter-cyclical and lead to a significant shift in occupation structure towards white-collar jobs.

Most relevant for our purpose, JS argue that the three recent recessions affected routine and non-routine workers in a dramatically different way. ${ }^{3}$ They show that routine employment generally drops more during recessions than non-routine employment. In addition, the three recent recessions are accompanied by no recovery in routine employment at all. Since the 1980s, per capita routine employment has been falling, not only as a fraction of total employment, but also in absolute terms. JS therefore refer to the mid 1980s as the start of the job polarization era.

The job polarization era is also marked by an overall drop in labor force participation and an increase in post-secondary education enrollment. As shown in Figure 1, labor force participation has been declining since the end of 1990s. Recessions appear to be important drivers of this decline.

\footnotetext{
${ }^{3}$ Using FRED data, JS define routine occupations as "sales and related occupations", "office and administrative support occupations", "production occupations", "transportation and material moving occupations", "construction and extraction occupations", and "installation, maintenance, and repair occupations". Non-routine cognitive occupations include "management, business, and financial operations occupations", "professional and related occupations". "Service occupations" are non-routine manual. We use their classification in our numerical analysis. See their paper for more details about classification and robustness.
} 
In particular, labor force participation fell from $66 \%$ to $63 \%$ following the Great Recession. At the same time, post-secondary education enrollment was almost flat from the mid 1970s up to mid 1990s, but increased afterwards, with a pronounced spike around the Great Recession. ${ }^{4,5}$ In our model, both the decreasing labor force participation and the increasing education enrollment are driven by the adoption of the skill-intensive technology.

(a) Labor force participation rate

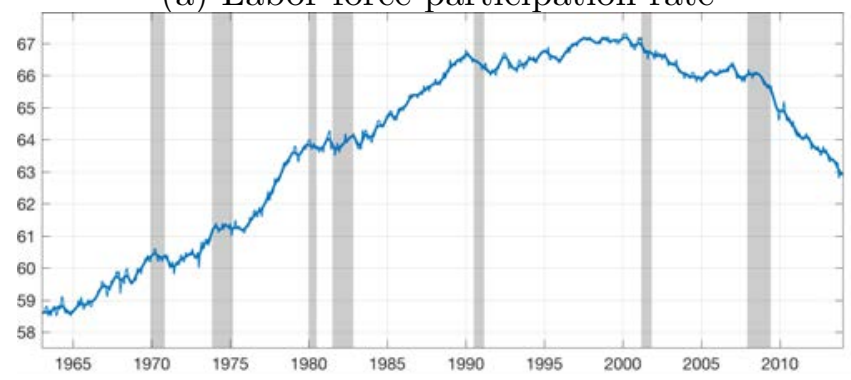

(b) Post-secondary education enrollment ratio

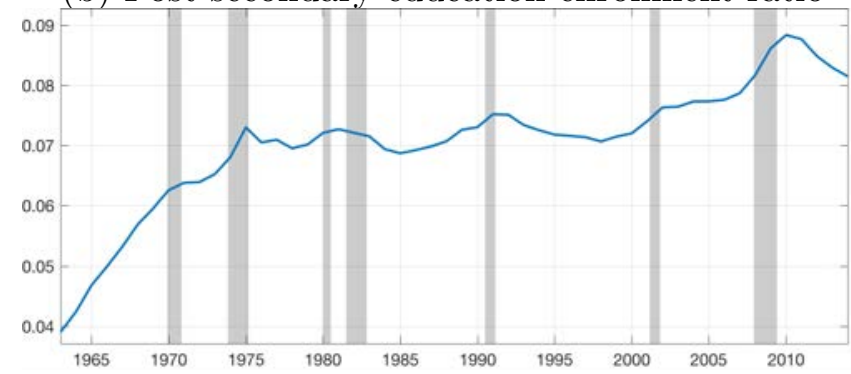

Figure 1: Labor force participation rate (from FRED) and post-secondary education enrollment ratio. Postsecondary education enrollment ratio is defined as total fall enrollment in degree-granting institutions (from National Center for Education Statistics) over civilian noninstitutional population (from FRED).

Besides this differential impact on the different skill categories of labor, recessions also have diverging effects on different types of investment. For example, a pronounced persistent decline in private investment that happened in the aftermath of the Great Recession is to a large extent driven by an unprecedented drop in residential investment. In contrast, as shown in Figure 2, investment in intellectual property, such as software and R\&D, as well as industrial and information processing equipment, tools that are used by skill-intensive firms, experienced a much smaller drop and recovered rapidly (see also Brynjolfsson and McAfee). In Appendix A we also show that world-wide shipments of industrial robots experienced a sharp increase immediately after the Great Recession.

(a) Private nonresidential investment by type

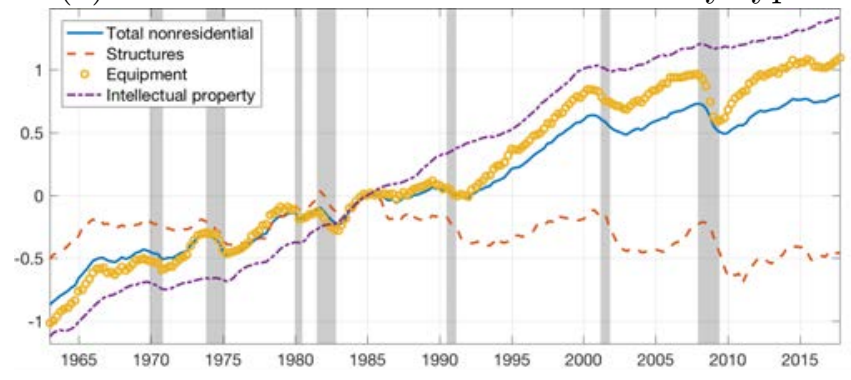

(b) Private equipment investment by type

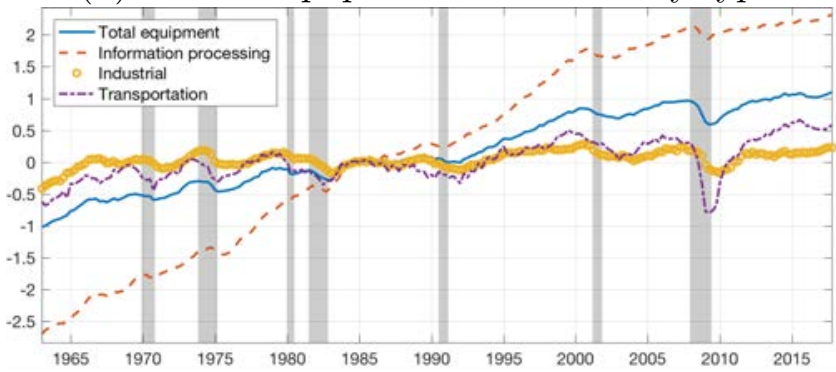

Figure 2: Log real per capita private investment by type (from NIPA Tables). The series are normalized to 0 in 1985.

\footnotetext{
${ }^{4}$ Correlation between the labor force participation and the post-secondary enrollment ratio seems to change sign around the start of the job polarization era. Between 1963 and 1984 the correlation is 0.84, while between 1985 and 2014 it is -0.63 .

${ }^{5}$ It is worth noticing that enrolled in post-secondary institutions do not necessarily complete their education. Thus, the dynamics of post-secondary enrollment and completion ratios might be different.
} 


\section{Model}

Time is discrete and goes on forever, $t=\{0,1, \ldots\}$. The economy is populated by a representative household that consists of a unit measure of workers. A worker is either low-skill or high-skill, and a low-skill worker can become high-skill through training. On the production side, a final good is produced with two kinds of inputs. The first one is "manual services" which can be produced using low-skill labor in non-routine manual tasks. The second input is "intermediates" which can be produced by combining capital and the two types of labor. ${ }^{6}$

Intermediates can be produced using one of two different technologies: an old technology that is low-skill intensive and a new technology that is high-skill intensive. All firms begin in period $t=0$ by using the old technology and, as the productivity of the new technology slowly improves, progressively switch to it. Adopting the new technology requires capital and high-skill labor, and the firm must stop production while the workplace is being reorganized. Below we describe the agents in greater detail.

\subsection{Representative household}

The representative household values final consumption goods using a constant relative risk aversion utility function with coefficient $\gamma$ and discounts future utility at a rate $b$. The household consists of a unit mass of atomistic workers, each endowed with one unit of labor. A fraction $h$ of them are high-skill and the remaining $u=1-h$ are low-skill. ${ }^{7}$ Low-skill workers can either work in production $\left(u_{p}\right)$, in which case they earn a wage $w_{u}$, or go to school as students $\left(u_{s}\right)$ in order to be trained and eventually become high-skill workers. While in training, low-skill workers are out of the labor force. High-skill workers are always employed, either in production $\left(h_{p}\right)$ for a wage $w_{h}$, or in schools as teachers $\left(h_{s}\right)$. The household also owns the capital stock $k$ and either uses it to train workers $\left(k_{s}\right)$ or rents it out to firms for production $\left(k_{p}\right)$ at a rate $r$.

Each period, the abilities of a fraction $\delta_{h}$ of high-skill workers are rendered obsolete and they

\footnotetext{
${ }^{6}$ Our definition of two different inputs is similar to Autor and Dorn (2013). It distinguishes between two broad types of tasks implemented by low-skill workers. Routine occupations required to produce intermediates are relatively easy to automate or offshore (e.g., secretaries, paralegals, laborers). Non-routine manual occupations in manual services, such as janitors or barbers, are not.

${ }^{7}$ Our definition of high skill is related to ability to implement non-routine cognitive tasks and not directly to education level. Although the two are doubtlessly positively correlated, they are not the same (see JS for a discussion). Nevertheless, as discussed in Section 4, we use post-secondary education data for our calibration purposes.
} 
become low-skill. The dynamics of the mass of high-skill workers is

$$
h^{\prime}=\left(1-\delta_{h}\right) h+\phi\left(k_{s}, h_{s}, u_{s}\right), h^{\prime} \in[0,1]
$$

where $\phi(k, h, u)$ is the training technology. As in Perli and Sakellaris (1998), we assume that

$$
\phi(k, h, u)=s k^{\beta_{s}}\left(\mu_{s} h^{\rho_{s}}+\left(1-\mu_{s}\right) u^{\rho_{s}}\right)^{\frac{1-\beta_{s}}{\rho_{s}}},
$$

where $\beta_{s}$ is the capital intensity of the training sector, $\mu_{s}$ is the high-skill intensity and $\rho_{s}$ relates to the elasticity of substitution between high-skill and low-skill workers (teachers and students).

The household owns the firms and receives their profits $\Pi$ every period. It also invests in new capital subject to quadratic adjustment costs $\varphi(i, k)=\frac{\chi}{2}\left(\frac{i}{k}-\delta_{k}\right)^{2} k$. Capital depreciates at a rate $\delta_{k}$, so that its law of motion is

$$
k^{\prime}=\left(1-\delta_{k}\right) k+i \text {. }
$$

Denoting by $\Omega$ the aggregate state of the economy (which will be fully described later), the dynamic problem of the household is

$$
W(h, k, \Omega)=\max _{\substack{h^{\prime}, k^{\prime}, h_{s}, h_{p}, u_{s}, u_{p}, k_{s}, k_{p}}} \frac{c^{1-\gamma}}{1-\gamma}+b \mathbb{E}\left[W\left(h^{\prime}, k^{\prime}, \Omega^{\prime}\right) \mid \Omega\right]
$$

subject to the budget constraint

$$
c+i+\varphi(i, k)=w_{h}(\Omega) \cdot h_{p}+w_{u}(\Omega) \cdot u_{p}+r(\Omega) \cdot k_{p}+\Pi(\Omega)
$$

and the laws of motion (1) for high-skill workers and (2) for capital and to an aggregate law of motion $\Omega^{\prime}=G(\Omega)$ for $\Omega$.

\subsection{Firms and technologies}

\subsubsection{Final goods producer}

There is a competitive industry that produces the final consumption good by combining intermediates (from both old and new firms) with manual services. We normalize the price of the final 
good to 1. The static problem of a firm in this industry is

$$
\max _{y_{i, n} ; y_{i, o} ; y_{m s}} e^{z}\left[\left(y_{i, n}^{\theta}+y_{i, o}^{\theta}\right)^{\frac{\epsilon}{\theta}}+y_{m s}^{\epsilon}\right]^{\frac{1}{\epsilon}}-P_{o}(\Omega) y_{i, o}-P_{n}(\Omega) y_{i, n}-P_{s}(\Omega) y_{m s}
$$

where $y_{i, n}$ is the amount of intermediates produced with the new technology, $y_{i, o}$ is the amount of intermediates produced with the old technology and $y_{m s}$ is the input flow from manual services. ${ }^{8}$

In the spirit of the endogenous growth models a-la Romer (1990) and Grossman and Helpman (1991), we assume that the new technology allows intermediate firms to produce a potentially different variety of goods, implying imperfect substitutability between the two $(\theta<1)$. This assumption captures the fact that new labor-saving technologies often do not fully replace the products of old technologies. While digital sound has become much more wide-spread than its analog counterpart, demand for LPs is still nontrivial, as some music connoisseurs prefer the latter. Locally-grown organic foods are not fully substituted away by genetically modified products. Importantly, however, we show in Appendix B that our results generally extend to the case of perfect substitutability, $\theta=1$.

Aggregate total factor productivity $z$ follows an AR(1) process such that

$$
z^{\prime}=\rho z+\sigma_{z} \epsilon_{z}^{\prime}, \text { where } \epsilon_{z} \sim \operatorname{iid} \mathcal{N}(0,1)
$$

\subsubsection{Intermediates producers}

There is a unit mass of atomistic intermediates producers. These firms can operate using either the old or the new technology (and therefore are referred to as old and new firms), which we index by $j=\{o, n\}$. They combine capital $k$, high-skill labor $h$ and low-skill labor $u$ using the following production function

$$
F_{j}\left(A_{j}, h, u, k\right)=A_{j}\left[k^{\beta}\left(h^{\mu_{j}} u^{1-\mu_{j}}\right)^{1-\beta}\right]^{\alpha}, \quad j=\{o, n\}
$$

where $\beta$ is capital intensity, $A_{j}$ is total factor productivity, $\mu_{j}$ captures the skill intensity of the production function, and $\alpha<1$ is the decreasing returns to scale parameter. We use $\pi_{j}$ to denote

\footnotetext{
${ }^{8}$ We implicitly assume that the share parameters in the CES aggregators in (4) are equal to 1 . This is without loss of generality given our calibration of the relative productivities of the three technologies.
} 
the profits of a firm operating technology $j$ so that

$$
\pi_{j}(\Omega)=\max _{h, u, k} P_{j}(\Omega) F_{j}\left(A_{j}, h, u, k\right)-w_{h}(\Omega) \cdot h-w_{u}(\Omega) \cdot u-r(\Omega) \cdot k
$$

where $P_{j}(\Omega)$ is price of intermediates of type $j$.

The old and the new technology differ in two ways. First, the new technology is relatively more high-skill-intensive than the old one $\left(\mu_{n}>\mu_{o}\right)$. Second, their productivities are different $\left(A_{n} \neq A_{o}\right)$. At $t=0$ the new technology is not available $\left(A_{n}=0\right)$ and all agents consider its arrival as a zero probability event. All firms are using the old technology. Over time, technological progress favors the new technology such that $A_{n}$ grows faster than $A_{o}$. This induces firms to switch from the old to the new technology. Since the new technology is more high-skill intensive, technological adoption increases the demand for high-skill workers, which puts upward pressure on their wages. As a result, more low-skill workers enter the training process and the overall skill level in the economy increases. Without loss of generality, in what follows we assume that $A_{o}=1$.

Switching from the old to new technology is costly and risky. A firm that attempts to switch does not produce during the current period and successfully acquires the new technology with probability $\xi(h, k), \xi \in[0,1), \xi_{h h}, \xi_{k k}<0<\xi_{h}, \xi_{k} \cdot{ }^{9}$ A firm can increase its odds of successful adoption by hiring more high-skill workers $h$ or by renting more capital $k{ }^{10}$ Following Andolfatto and MacDonald (1998), we assume that

$$
\xi(k, h)=1-\exp \left(-\eta k^{\beta_{a}} h^{1-\beta_{a}}\right) .
$$

Since a new firm never switches back to the old technology, its value is simply

$$
V_{n}(\Omega)=\pi_{n}(\Omega)+\mathbb{E}\left[M\left(\Omega, \Omega^{\prime}\right) V_{n}\left(\Omega^{\prime}\right) \mid \Omega\right]
$$

where $M\left(\Omega, \Omega^{\prime}\right)$ is the stochastic discount factor of the representative household.

In contrast, an old firm must decide each period whether to attempt a technology switch or to

\footnotetext{
${ }^{9} \mathrm{We}$ assume that the technology adoption has a probabilistic nature to capture, in a tractable way, that the adoption process might be longer than one period of the model, which is taken to be one year. Brynjolfsson, Malone, Gurbaxani, and Kambil (1994) and Brynjolfsson and Hitt (2003) find that it takes several years for a firm to fully adopt computer technology.

${ }^{10}$ The importance of high-skill labor (e.g., management and IT consultants) for technology adoption is emphasized by Nelson and Phelps (1966) and Greenwood and Yorukoglu (1997).
} 
produce with its current technology. As a result, its value is

$$
V_{o}(\Omega)=\max \left\{V_{o}^{p}(\Omega) ; V_{o}^{a}(\Omega)\right\},
$$

where the value of production is

$$
V_{o}^{p}(\Omega)=\pi_{o}(\Omega)+\mathbb{E}\left[M\left(\Omega, \Omega^{\prime}\right) V_{o}\left(\Omega^{\prime}\right) \mid \Omega\right]
$$

and the value of attempting to adopt the new technology is

$$
\begin{aligned}
V_{o}^{a}(\Omega)=\max _{h, k}\{ & -w_{h}(\Omega) h-r(\Omega) k+\xi(h, k) \mathbb{E}\left[M\left(\Omega, \Omega^{\prime}\right) V_{n}\left(\Omega^{\prime}\right) \mid \Omega\right] \\
& \left.+(1-\xi(h, k)) \mathbb{E}\left[M\left(\Omega, \Omega^{\prime}\right) V_{o}\left(\Omega^{\prime}\right) \mid \Omega\right]\right\}
\end{aligned}
$$

In what follows, we denote the masses of producing new and old firms by $m_{n}$ and $m_{o}$, respectively. The remaining fraction, $1-m_{n}-m_{o}$, are in the adoption process and are therefore not producing.

\subsubsection{Manual services producer}

There is a competitive representative firm producing manual services using low-skill workers. As in Autor and Dorn (2013), its production function is $F_{m s}(u)=A_{m s} u$ such that it maximizes

$$
\max _{u} P_{m s}(\Omega) F_{m s}(u)-w_{u}(\Omega) u
$$

where $P_{m s}(\Omega)$ is the price of services.

\subsection{Competitive equilibrium}

The set of aggregate state variables $\Omega$ contains the aggregate capital stock $K$, the mass of highskill workers $H$, the mass of firms producing intermediates which operate the new technology $m_{n}$, the productivity of the new technology $A_{n}$ and the productivity of the final goods producer $z$. We are ready to define a competitive equilibrium in this economy.

Definition 1 A recursive competitive equilibrium is a collection of value functions for the firms $V_{o}, V_{o}^{p}, V_{o}^{s}, V_{n}$ and for the household $W$, and their associated optimal decisions; a collection of 
prices $w_{h}, w_{u}, r, P_{o}, P_{n}, P_{m s}$ and aggregate laws of motion $G$, such that

1. the value functions and the optimal decisions solve problems 3, 4, 5, 6 and 7;

2. the markets for high-skill and low-skill labor and the market for capital clear:

$$
\begin{gathered}
H_{p}=m_{n} h_{n}+m_{o} h_{o}+\left(1-m_{n}-m_{o}\right) h_{a}, \\
U_{p}=m_{n} u_{n}+m_{o} u_{o}+U_{m s}, \\
K_{p}=m_{n} k_{n}+m_{o} k_{o}+\left(1-m_{n}-m_{o}\right) k_{a}, \\
H=H_{p}+H_{s}, \\
U=U_{p}+U_{s}, \\
1=H+U, \\
K=K_{p}+K_{s},
\end{gathered}
$$

where $h_{j}, u_{j}, k_{j}, j \in\{o, n\}$ denote the demand for high-skill labor, low-skill labor and capital, respectively, of old and new firms; $h_{a}, k_{a}$ denote the demand for high-skill labor and capital of firms adopting the new technology; $U_{m s}$ is the demand for low-skill labor of the manual services representative producer; $H_{s}, U_{s}, K_{s}$ denote respectively the amounts of high-skill labor, low-skill labor and capital used in the training process;

3. the law of motion $G$ is consistent with individual decisions.

\section{Parametrization}

We parametrize the model to match features of the United States economy since the middle of the 1980s, the beginning of the job polarization era. One period is one year. Below, we explain how the parameters are picked and Table 1 summarizes their values.

\section{Business cycle shocks}

The persistence and the standard deviation of the business cycle shocks, $\rho_{z}$ and $\sigma_{z}$, are set to match the first order autocorrelation and the volatility of HP-filtered real GDP per capita. ${ }^{11}$ We find $\rho_{z}=0.85$ and $\sigma_{z}=0.025$. The persistence value is close to what is normally used in the

\footnotetext{
${ }^{11}$ We match the moments of the initial steady state of the economy with their data counterparts between 1947 and 1985. Recall that the job polarization era, associated in our model with the arrival of the new technology, started around the mid 1980s, as argued by JS.
} 
RBC literature (Cooley and Prescott, 1995). The standard deviation $\sigma_{z}$ is somewhat larger than usual values. Since, in the model, there is no labor-leisure choice, larger fluctuations in exogenous productivity are necessary to match aggregate output volatility. ${ }^{12}$

\begin{tabular}{|c|c|c|}
\hline Parameter & Value & Source/Target \\
\hline \multicolumn{3}{|l|}{ Business cycle shock } \\
\hline Aggregate shock persistence & $\rho_{z}=0.85$ & Autocorrelation of output \\
\hline Volatility of aggregate shock & $\sigma_{z}=0.025$ & Volatility of output \\
\hline \multicolumn{3}{|l|}{ Preferences } \\
\hline Risk aversion & $\gamma=1.0$ & Log utility \\
\hline Time discounting & $b=0.96$ & $4 \%$ annual interest rate \\
\hline \multicolumn{3}{|l|}{ Production sector } \\
\hline DRS parameter & $\alpha=0.9$ & Basu and Fernald (1997) \\
\hline Share of capital & $\beta=0.3$ & Average labor share \\
\hline Share of $H$ in old technology & $\mu_{o}=0.45$ & Routine employment in 1985 \\
\hline Share of $H$ in new technology & $\mu_{n}=0.83$ & C-S dispersion in routine wage share \\
\hline EoS between new and old goods & $\frac{1}{1-\theta}=4$ & Bernard, Eaton, Jensen, and Kortum (2003) \\
\hline EoS between goods and services & $\frac{1}{1-\epsilon}=0.167$ & Buera, Kaboski, and Rogerson (2015) \\
\hline Productivity of manual services & $A_{m s}=5.91$ & Non-routine manual employment in 1985 \\
\hline Physical capital depreciation & $\delta_{k}=0.1$ & $10 \%$ annually \\
\hline Adjustment cost parameter & $\chi=0.25$ & Investment volatility \\
\hline \multicolumn{3}{|l|}{ Schooling/training } \\
\hline Share of capital & $\beta_{s}=0.1$ & Perli and Sakellaris (1998) \\
\hline EoS between $H$ and $U$ & $\frac{1}{1-\rho_{s}}=0.5$ & Perli and Sakellaris (1998) \\
\hline Share of $H$ in education & $\mu_{s}=0.0076$ & Student-teacher ratio \\
\hline Constant & $s=0.248$ & Post-secondary enrollment in 1985 \\
\hline High skill depreciation & $\delta_{h}=0.05$ & Heckman (1976) \\
\hline \multicolumn{3}{|l|}{ Technology adoption } \\
\hline Capital share & $\beta_{a}=0.3$ & Same as in production sector \\
\hline Ease of adoption & $\eta=1.5$ & Expected adoption lag is 3 years \\
\hline \multicolumn{3}{|l|}{ Technological progress } \\
\hline Initial impact & $A_{n}^{0}=0.1$ & \\
\hline Final value & $\bar{A}_{n}^{n}=1.5$ & Trends in non-routine cognitive, non-routine \\
\hline Length & $T_{\text {finish }}-T_{\text {start }}=75$ & \\
\hline
\end{tabular}

Table 1: Parametrization.

\section{Preferences}

The time discount rate $b$ is set to 0.96 , which implies a $4 \%$ annual interest rate. We set the risk aversion $\gamma$ to 1 .

\section{Production sector}

The returns to scale parameter for firms producing intermediates is set to $\alpha=0.9$, consistent with

\footnotetext{
${ }^{12}$ As discussed in Footnote 18, we solve the model assuming perfect foresight. All shocks are therefore completely unanticipated and the value of $\sigma_{z}$ does not affect the impulse response functions directly. The value of $\sigma_{z}$ does however matter for the calibration of other parameters of the model.
} 
the estimates of Basu and Fernald (1997). The capital share parameter is $\beta=0.3$, consistent with aggregate data. The share of high-skill labor in the old production technology is set to $\mu_{o}=0.45$ to match the fraction of routine employment in total employment at the beginning of the job polarization era. For the new technology, we set $\mu_{n}=0.83$ in order to match the cross-sectional dispersion in routine wage share in the total wage bill across intermediates producing firms to the value found by Zhang (2015). ${ }^{13}$ The elasticity of substitution between the new and old goods in the production of consumption goods is 4 , so that $\theta=0.75$, close to the estimates of Hsieh and Klenow (2014) and Bernard, Eaton, Jensen, and Kortum (2003). The elasticity of substitution between intermediates and manual services is 0.167 , which implies $\epsilon=-5$, in line with estimates of Buera and Kaboski (2009) and Herrendorf, Rogerson, and Valentinyi (2013). Productivity of manual services is set to $A_{m s}=5.91$ in order to match the employment share of non-routine manual labor in 1985. Physical capital depreciates at the rate of $\delta_{k}=0.1$. The adjustment cost parameter is set to $\chi=0.25$ to match the volatility of private investment.

\section{Training}

The calibration of the training technology is not straightforward. To the best of our knowledge, there is no empirical estimates of an aggregate training function that combines low and high-skill labor together with physical capital. Closest to our paper in this regard, Perli and Sakellaris (1998) consider an RBC economy with a human capital sector. Their human capital production technology is similar to ours and we therefore set the capital share to $\beta_{s}=0.1$ and the elasticity of substitution between high and low-skill labor to $\frac{1}{1-\rho_{s}}=0.5$. The latter value implies that high and low-skill labor are strong complements in the training sector. We set the relative weight of high-skill labor $\mu_{s}=0.0076$ in order to roughly match the teacher-student ratio in post-secondary education. $^{14}$ The productivity $s=0.248$ is set to match the number of low-skill agents in the training process $U_{s}$ in the initial steady state to the fraction of the civilian noninstitutional population in post-secondary education in 1985. Finally, the skill depreciation rate is set to $\delta_{h}=0.05 .^{15}$

\footnotetext{
${ }^{13}$ Zhang (2015) sorts firms based on this characteristic and finds that the spread between the highest and the lowest quantiles is 0.37 . In our model, there exists a trivial cross-section of firms among intermediates producers, with old firms having a higher routine wage share. $\mu_{n}=0.83$ implies that the difference in the routine wage share between new and old firms is close to 0.37. This value stays almost constant along the transition path.

${ }^{14}$ According to the National Center for Education Statistics, this ratio was slightly below $6 \%$ in the $1980 \mathrm{~s}$ and has increased up to $7.6 \%$ by the $2010 \mathrm{~s}$. We set $\mu_{r}$ so that in the initial steady state $\frac{H_{s}}{U_{s}}=0.07$. Due to absence of reliable data, we ignore other forms of training besides higher education. However, as argued by Perli and Sakellaris (1998), higher education is responsible for up to $90 \%$ of total investment in human capital.

${ }^{15}$ In the model $\delta_{h}$ can be interpreted as the retiring rate, which is currently around $3 \%$ in the USA. One can assume that every period a fraction $\delta_{h}$ of the total labor force $\bar{L}$ retires and is immediately replaced by low-skill workers. At the same time, $\delta_{h}$ should include the rate of skill obsolescence. A literature estimates the depreciation rate of human capital. Despite a large variation, $\delta_{h}=0.05$ is close to what is normally found (Heckman, 1976 and
} 


\section{Technology adoption}

An old firm attempting to adopt the new technology is successful with probability $\xi(k, h)=$ $1-\exp \left(-\eta k^{\beta_{a}} h^{1-\beta_{a}}\right)$. As for the earlier production technology, we set the capital intensity to $\beta_{a}=0.3$. The parameter $\eta>0$ governs the importance of capital and high-skill labor for the technology adoption. If $\eta$ is large, then only a few workers and small amounts of capital are required to get the transition probability close to its maximum level of 1 . On the contrary, a small value of $\eta$ implies a large demand for high-skill labor and capital among adopting firms. Thus, smaller $\eta$ 's are associated with larger adoption costs. We set $\eta=1.5$. Along the transition path, the resulting probability of successful technology adoption is around $0.33{ }^{16}$

\section{Technological progress}

The decision of the firms whether to adopt the new technology or not depends on the gap between $A_{o}$ and $A_{n}$. We therefore normalize $A_{o}=1$ and focus on the evolution of $A_{n}(t)$ which we parametrize as follows

$$
A_{n}(t)= \begin{cases}0, & t<T_{\text {start }}, \\ A_{n}^{0}+\left(\bar{A}_{n}-A_{n}^{0}\right) \frac{1-\exp \left(\frac{T_{\text {start }}-t}{T_{\text {finish }}-T_{\text {start }}}\right)}{1-\exp (-1)}, & t \in\left[T_{\text {start }}, T_{\text {finish }}\right], \\ \bar{A}_{n}, & t>T_{\text {finish }},\end{cases}
$$

where $T_{\text {start }}$ denotes the arrival of the new technology (the mid 1980s in our case, corresponding to the start of the job polarization era in JS). Upon arrival, its productivity is $A_{n}^{0}$ and it increases over time until it reaches $\bar{A}_{n}>A_{n}^{0}$ by at $t=T_{\text {finish }}$.

The shape of the $A_{n}(t)$ process is inspired by the general purposes technology (GPT) literature (e.g., Bresnahan and Trajtenberg, 1995). The initial impact of the new technology $A_{n}^{0}$ can be modest. Later on, a sequence of smaller innovations enhance the productivity of the new technology. As a result, the technology reaches its peak $\bar{A}_{n}$ after a (potentially long) lag $T_{\text {finish }}-T_{\text {start }}$. This is typical of GPTs (Helpman, 1998), including the ICT (Jovanovic and Rousseau, 2005).

In our baseline analysis, we set $A_{n}^{0}=0.1, \bar{A}_{n}=1.5, T_{\text {finish }}-T_{\text {start }}=75 .{ }^{17}$ These parameters are

Mincer and Ofek, 1982).

${ }^{16}$ Consistent with this number, Brynjolfsson, Malone, Gurbaxani, and Kambil (1994) and Brynjolfsson and Hitt (2003) find that it normally takes several years for a firm to fully adopt computer technology.

${ }^{17}$ GPTs are known to become fully productive only after a significant lag. For example, David (1990) argues that electricity delivered a major economic boost only in the 1920s, 40 years after the first generating station came into being. Crafts (2004) finds a lag of almost 100 years for the steam related technologies. Using asset prices, Ward (2015) predicts that it will take around 50 years for the IT to be fully absorbed by the economy. 
chosen to match the trend in the non-routine cognitive employment share reasonably well. Our choice of $\bar{A}_{n}$ and $T_{\text {finish }}-T_{\text {start }}$ is not unique to achieve this. A longer/shorter progress with a higher/lower terminal value can match the same series. Since the goal of the paper is not to predict when the growth of $A_{n}(t)$ will stop, we do not take a strong stand on precise values of $\bar{A}_{n}$ and $T_{\text {finish }}-T_{\text {start }}$. Importantly, our results on interactions of routine-biased technological change with business cycles are unchanged if we simultaneously vary $T_{\text {finish }}-T_{\text {start }}$ and $\bar{A}_{n}$ to match the observed non-routine cognitive employment share.

\section{$5 \quad$ Numerical results}

This section presents our main numerical results. ${ }^{18}$ Section 5.1 explains the economic forces at work. In Section 5.1.1, we discuss the transition from the old steady state to the new one created by the arrival of the new technology. Section 5.1.2 describes the differential impacts of business cycles on the economy in the pre- and during transition periods. Finally, Section 5.2 investigates how recessions interact with the adoption of the new technology.

\subsection{Economic forces at work}

\subsubsection{Transition paths}

We begin by investigating how the arrival of the new technology affects the economy without business cycle shocks. The path for the exogenous process $A_{n}$ is shown in Figure 3. The initial shock is small, representing the idea that a new fundamental technology is hardly productive right after its arrival. As the new technology gradually becomes better, $A_{n}$ increases and reaches its steady-state level after 75 years.

Figure 4 shows how the introduction of the new technology affects the technology acquisition decision of the firms and the occupational choices decision of the workers. We see that, over time, firms adopt the new technology as its productivity increases (left panel). ${ }^{19}$ Since the new

\footnotetext{
${ }^{18}$ Since the competitive economy is efficient, we solve the problem of a social planner that maximizes the welfare of the representative household. Given the complexity of the economy, we solve the model using a perfect foresight approach. In particular, we assume that all business cycle shocks are completely unexpected. To verify the validity of this approach, we have also solved a simpler version of the fully stochastic model globally. The perfect foresight approach does not matter much for the predictions of the model but significantly decreases the complexity of the computations. We further address impacts of recession anticipation in Appendix C.

${ }^{19}$ In principle, the mass of old firms is never zero in the terminal steady state due to imperfect substitutability
} 


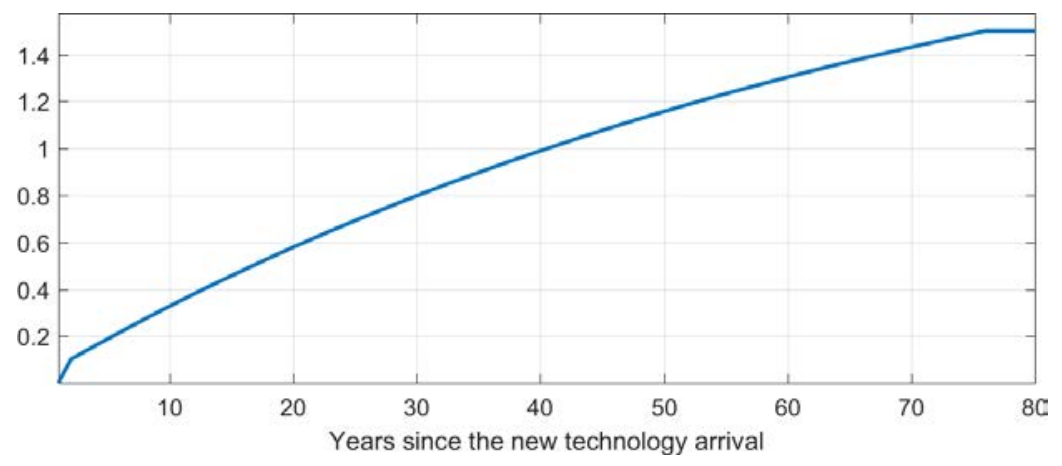

Figure 3: The productivity $A_{n}(t)$ of the new technology.

technology is relatively more skill-intensive, low-skill workers respond accordingly and start to train to acquire new skill (right panel). As a result, routine manual employment (low-skill workers employed in the intermediates production) declines.

Since the two inputs in the final consumption bundle are complementary, when productivity of intermediates go up, it is optimal also to increase output manual services. Consequently, low-skill employment in manual services increases gradually (the yellow dot-dashed curve in the right-hand panel of Figure 4). As we can see, the model is able to generate job polarization and, as we discuss in more details in Section 5.2, it does a fairly good job in explaining these patterns quantitatively.

(a) Firms

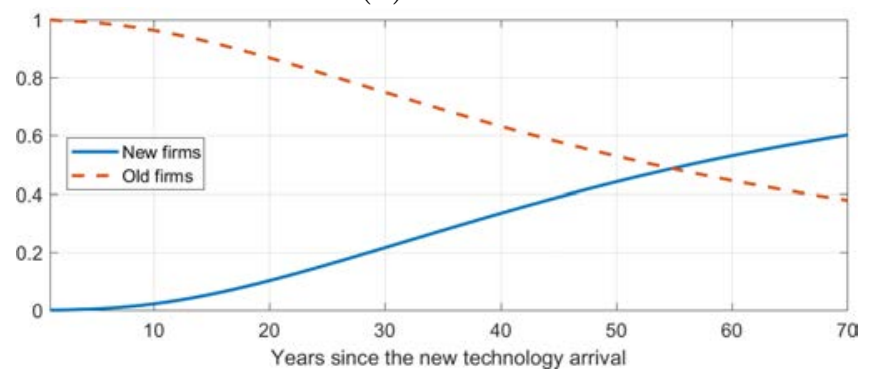

(b) Workers

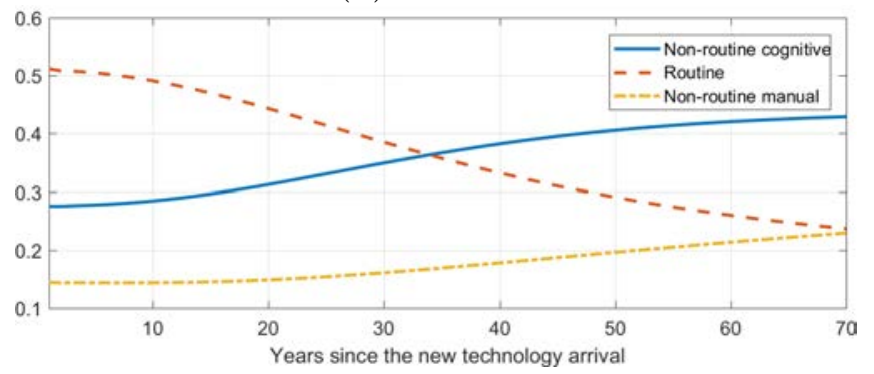

Figure 4: Transition upon arrival of the new technology.

Figure 5 illustrates other aspects of the technology adoption process. The top-left panel shows how the production of consumption goods $Y_{f}$ evolves over time. Despite the positive technological surprise at $t=0, Y_{f}$ does not respond immediately. For roughly 15 years $Y_{f}$ is almost unchanged and starts to grow only afterwards. This is due to the GPT nature of the new technology. The adoption of such a technology requires significant investment in reorganization of the workplace and in the accumulation of the required production factors. ${ }^{20}$ This is illustrated by the top-right between the new and old technologies. It however becomes very close to zero if $\bar{A}_{n} \gg A_{o}$. For our choice of parameter, the mass of old firms in the final steady state is 0.34 . The transition is largely finished in 100 periods after the arrival of the new technology.

${ }^{20}$ This is reminiscent of the infamous Solow productivity paradox. Due to large reorganization costs, the new technology starts to produce a sizable impact on the economy after a long lag. These reorganization costs are likely to be mismeasured in the GDP calculations to a large extent. See also Brynjolfsson (1993). 
and bottom panels of Figure 5. The top-right panel shows the ratio of total adoption costs $Y_{a}$ to final output $Y_{f}$. We use two measures of $Y_{a}$. The first measure, $Y_{a, 1}$, includes capital and high-skill labor rents in the training and adoption technologies. The second measure, $Y_{a, 2}$, also takes into account forgone profits due to firms being in the restructuring stage.

$$
\begin{aligned}
Y_{a, 1} & =w_{h}\left(H_{a}+H_{s}\right)+r\left(K_{a}+K_{s}\right), \\
Y_{a, 2} & =Y_{a, 1}+\frac{\partial Y_{f}}{\partial m_{o}}\left(\bar{m}-m_{n}-m_{o}\right) .
\end{aligned}
$$

The calibration implies that $Y_{a, 1}$ becomes as high as $2.70 \%$ of $Y_{f}$ around year 30 . Around the same time, unmeasured reorganization investment, captured in our model by foregone output due to old firms going through the adoption process, account for about $0.28 \%$ of $Y_{f}$. Notice that in the new steady state adoption costs are higher than in the initial steady state (1.43\% vs $0.98 \%)$. In the new steady state, the number of high-skill workers is higher and more training is therefore required.

The bottom panel of Figure 5 further illustrates that the period after the arrival of the technology is marked by a diversion of resources away from the production of final good. The total mass of active firms and the overall number of workers in the production sector are shrinking for around 30 years (the yellow dot-dashed and red dashed lines, respectively). High-skill labor is required for the firms' reorganization and training of low-skill workers. At the same time, low-skill workers start to train in larger numbers, which contributes to a drop in the labor force participation (the blue solid line) and to an increase in school enrollment. ${ }^{21}$ These two phenomena have been visible in the U.S. data for the last two decades.

In particular, the model predicts that the labor force participation drops by around 4 p.p. between 1985 and 2017, which is comparable to the number observed in the data (Figure 1, left panel). The model predicts a steady decline in the labor force participation, while in the data it was growing until the late 1990s and plummeted afterwards. Since the paper abstracts from several important aspects (e.g., labor force participation among women, which was increasing until the late 1990s), it cannot match the whole dynamics of the series.

Over the same period, the model-implied school enrollment ratio increased from $6.9 \%$ in 1985 up to $10.2 \%$ in 2014 . This is larger than in the data, where the ratio increased from $6.9 \%$ up to $8.2 \%$ (Figure 1, right panel). There are two reasons why the model-implied increase is higher. First, in the model, schooling represents all types of training, including on-the-job training and various job

\footnotetext{
${ }^{21}$ Recall that in the model the only labor force non-participants are low-skill workers in schools $U_{s}$.
} 
(a) Output, $Y_{f}$

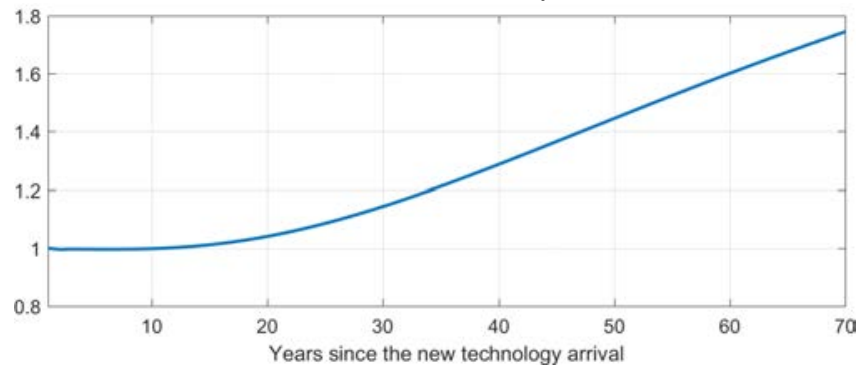

(b) Adoption cost to output, $\frac{Y_{a}}{Y_{f}}$

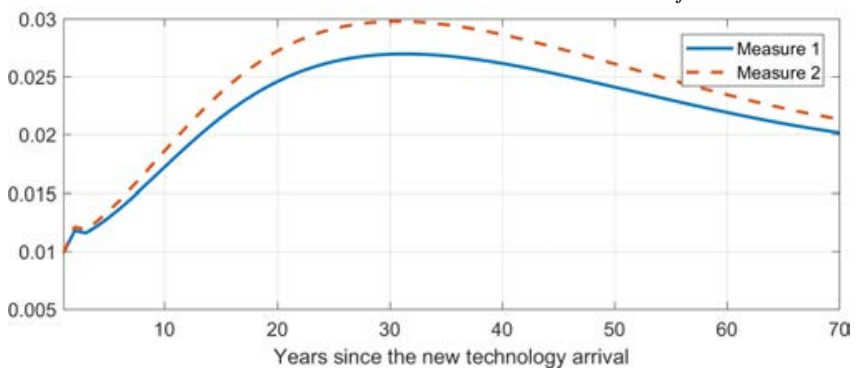

(c) Resource allocation

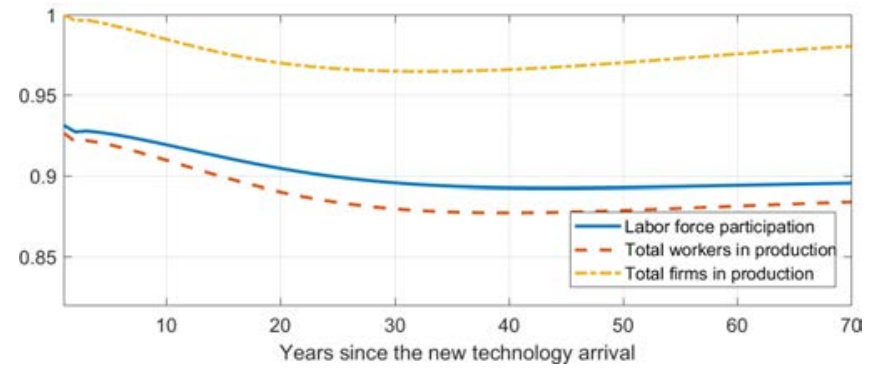

Figure 5: Top-left panel shows output of the final good sector $Y_{f}$. Top-right panel shows two measures of adoption costs $Y_{a}$ (see text) as a fraction of the final good sector production $Y_{f}$. The bottom panel illustrates how the allocation of resources vary over time.

training programs, while the data counterpart takes into account only formal higher education. Second, in the model all workers are either employed or in schools, and a decrease in the number of employed low-skill workers necessarily leads to an increase in the number of employed high-skill workers (with a time lag). This approach misses a recent increase in non-employment among lowskill workers (Cortes, Jaimovich, Nekarda, and Siu, 2014 and Cortes, Jaimovich, and Siu, 2016) that is unrelated to education. ${ }^{22}$ Demographic changes, such as population aging, might also play a role (Autor and Dorn, 2009).

In the model, job polarization is driven by two main forces. First, the number of low-skill workers goes down along the transition path. As a result, the supply of routine workers diminishes. Second, at each point in time, the propensity of a low-skill worker to take a routine job (i.e., a job in an old or a new intermediates producing firm) goes down. On the one hand, she is more likely to attend school. Conditional on not attending school, on the other hand, she is more likely to do a manual services job. Formally, the routine employment $R$ can be written as

$$
R=U\left(1-p_{s c}-p_{n r m}\right)
$$

where $U$ is the total supply of low-skill workers in the economy, $p_{s c}$ and $p_{n r m}$ are the probabilities that a low-skill worker is in the training process or employed in manual services. Change in

\footnotetext{
${ }^{22}$ Aguiar, Bils, Charles, and Hurst (2017) emphasize the importance of video games and other recreational computer activities in reducing the labor supply of young males.
} 
routine employment $\Delta R$ therefore can be decomposed into a composition and a propensity effect,

$$
\Delta R=\underbrace{\Delta U\left(1-p_{s c}-p_{n r m}\right)}_{\text {Composition }}-\underbrace{U \Delta\left(p_{s c}+p_{n r m}\right)}_{\text {Propensity }}-\underbrace{\Delta U \Delta\left(p_{s c}+p_{n r m}\right)}_{\text {Interaction }} .
$$

Table 2 presents the decomposition of the overall decline in $R$ between changes in $U, p_{s c}$ and $p_{n r m}$.

\begin{tabular}{|c|c|c|c|c|c|c|c|}
\hline & \multirow[t]{2}{*}{$R_{1989}$} & \multirow[t]{2}{*}{$R_{2014}$} & \multirow[t]{2}{*}{$\Delta R$} & \multirow[t]{2}{*}{ Composition } & \multicolumn{2}{|c|}{ Propensity } & \multirow[t]{2}{*}{ Interaction } \\
\hline & & & & & Schooling & NRM & \\
\hline$R$ & $50.47 \%$ & $38.61 \%$ & $-11.86 \%$ & $-5.18 \%$ & $-3.96 \%$ & $-3.49 \%$ & $0.76 \%$ \\
\hline
\end{tabular}

Table 2: Model-implied change in routine employment $R$ between 1989 and 2014 . The years are chosen as in Cortes, Jaimovich, and Siu (2016).

The model implies that both the composition and the propensity effects are important for job polarization, with the latter force being more significant. This is consistent with the micro evidence provided by Cortes, Jaimovich, Nekarda, and Siu (2014) and Cortes, Jaimovich, and Siu (2016).

\subsubsection{Business cycles}

We now compare the responses of the economy to business cycle shocks before and after the introduction of the new technology. We investigate this question by first shocking the economy with an adverse $z$ shock along the transition path. We consider a large 2.5 standard deviation $z$ shock happening 23 years after the new technology arrival. Assuming that the technology arrived around 1985, the timing and the magnitude of the recession in the model corresponds to the Great Recession in the data. We then compare the outcome of this first experiment with the response of the economy to the same shock before the new technology was available. ${ }^{23}$

The results are shown in Figure 6. We see that before, the arrival of the new technology, the training of workers is counter-cyclical (the red dashed curves in panels (f)-(h)), as is typical of RBC models with human capital (e.g., Perli and Sakellaris, 1998). The intuition is straightforward. During recessions, workers are relatively inefficient in production and the economy therefore uses these periods to accumulate human capital.

\footnotetext{
${ }^{23}$ The arrival of the new technology changes the structure of the production technology. In general, this can affect the economy's response to business cycle shocks by itself. We verify that our results are driven by the interaction between the adoption decisions and the business cycle rather than by a different production technology. In Appendix D we consider the impulse response functions to the same $z$ shock in the new steady state when the economy as fully transitioned. We find that the responses are much closer to their pre-transition counterparts than to the ones observed along the transition path.
} 
This process is however amplified along the transition path for two reasons. In addition to the mechanism highlighted above, the household understands that, since firms also use the recession to adopt the new technology, the future demand for high-skill workers will increase. Economic downturns are therefore a perfect period to train the workforce for this increased demand. The second reason is that training and adoption are intensive in different factors, namely low and high-skill labor, which complement each other in the intermediates production. When firms start to adopt the new technology in recessions, they demand high-skill labor. This decreases the marginal productivity of low-skill workers who are in production and some of them therefore move into training. It turns out that the training-adoption complementarity is the main driver behind the additional investment in human capital that we observe during the recession. As discussed in Appendix E, when $\eta$ is high and adoption does not require much resources, counter-cyclical reallocation of low-skill labor towards training is much closer to the pre-transition case.

In sum, an adverse productivity shock to the final good sector leads to a more active reallocation of factors during the technological transition than before the arrival of the new technology. In particular, panels $(\mathrm{g})$ and $(\mathrm{h})$ show that training is now absorbing more resources. Reallocation towards adopting firms (panel (i)), which is completely absent in the initial steady state, is responsible for roughly half of the additional drop in the total production employment (panel (f)).

Panels (j)-(l) of Figure 6 illustrate the production and adoption decisions of the firms. Since the technology change requires a temporary halt in production, it is more attractive during economic downturns when profits are lower. Panel $(\mathrm{k})$ shows that the mass of old firms drops by 3.5 p.p. as a result of the negative $z$ shock. This drop leads to a lagged increase in the mass of firms operating the new technology, as shown in panel $(\mathrm{j})$.

The counter-cyclical adoption and training incentives are mitigated by the consumption smoothing motives of the representative household. However, this effect turns out to be relatively small for conventional values of the intertemporal elasticity of substitution.

As a result of the increased technological adoption and additional workers training triggered by the recession, the drops in output, consumption and investment are all significantly more pronounced during the technological transition than before the arrival of the technology (panels (b)-(d) in Figure 6). ${ }^{24}$

\footnotetext{
${ }^{24}$ In Appendix F we verify that recessions during technological transitions are still deeper, even after adjusting the output measure for training and adoption costs.
} 
(a) Productivity, $z$

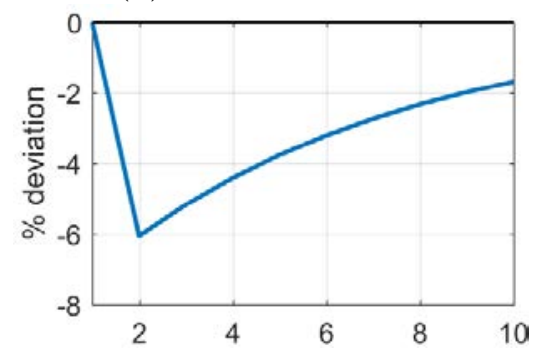

(d) Investment, $I$

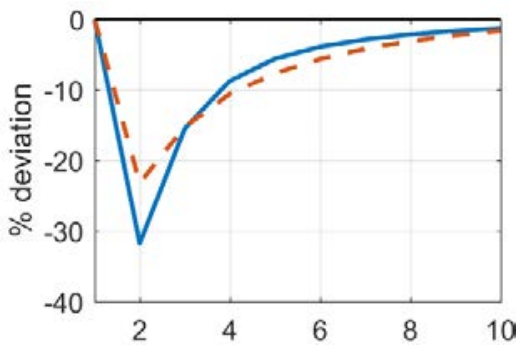

(g) L-S in training, $U_{s}$

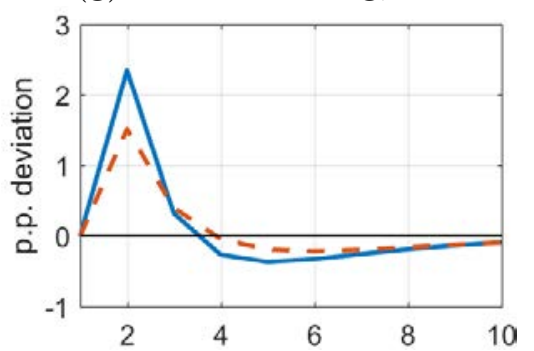

(j) New firms, $m_{n}$

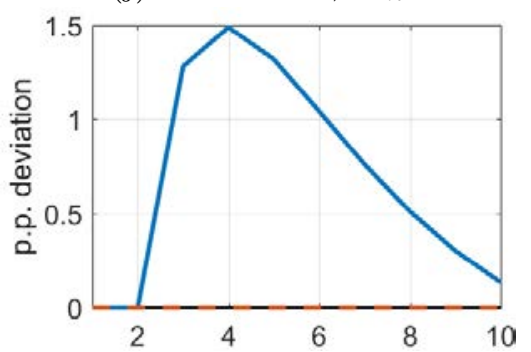

(b) Output, $Y_{f}$

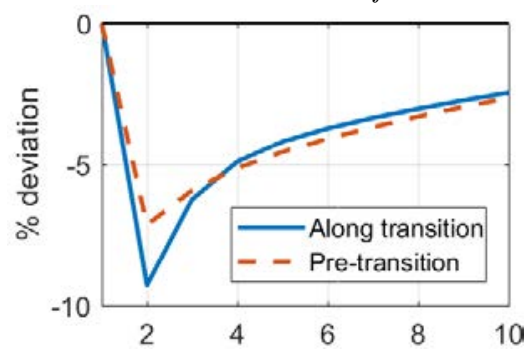

(e) Capital, $K$

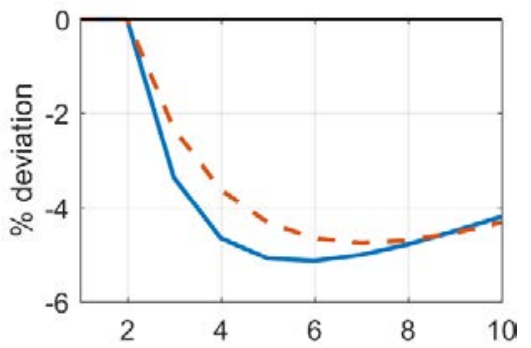

(h) H-S in training, $H_{s}$

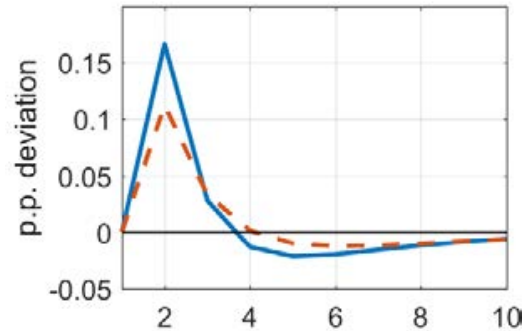

(k) Old firms, $m_{o}$

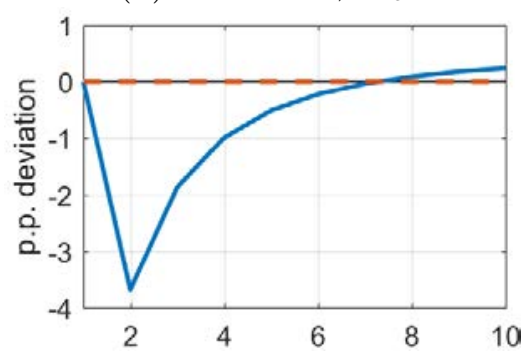

(c) Consumption, $C$

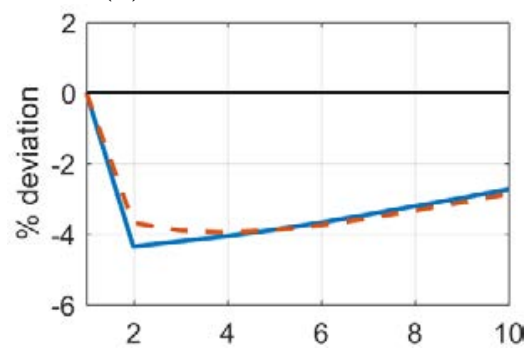

(f) Production empl, $H_{p}+U_{p}$

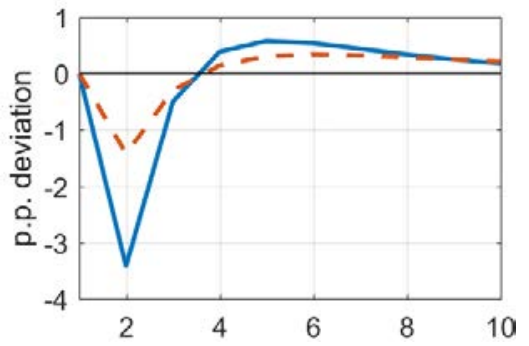

(i) H-S in adoption, $H_{a}$

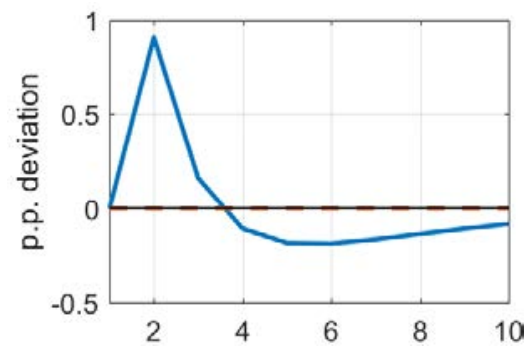

(l) Active firms, $m_{n}+m_{o}$

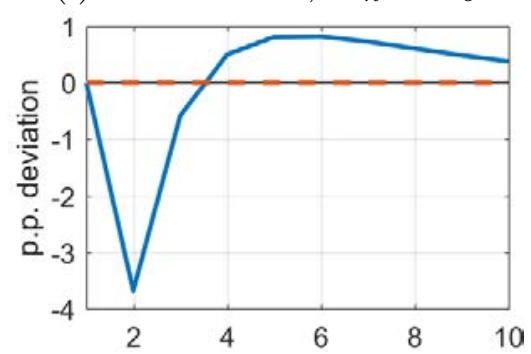

Figure 6: IRFs to a negative $z$ shock. Graphs are plotted relative to no $z$-shock scenario.

\subsection{Routine-biased technological change and the Great Recession}

We now investigate whether the model can rationalize both the long-run trend in the employment shares induced by routine-biased technological change and the importance of recessions in generating job polarization. We use the same definitions and data sources as JS. Particularly, non-routine cognitive/non-routine manual/routine jobs in their definition correspond to high-skill/low-skill manual services/low-skill intermediates jobs in the model. Figure 7 shows the results.

We consider the impact of a negative 2.5 standard deviation $z$ shock 23 years after the technology arrival for the model-implied employment shares. Again, given our timing, this shock corresponds 
(a) Non-routine cognitive employment share

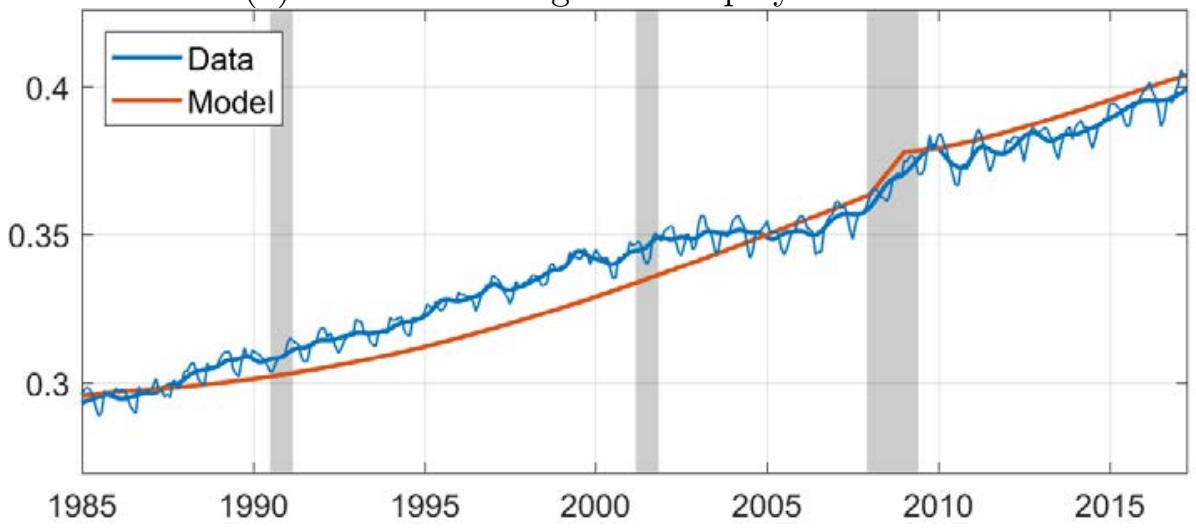

(b) Non-routine manual employment share

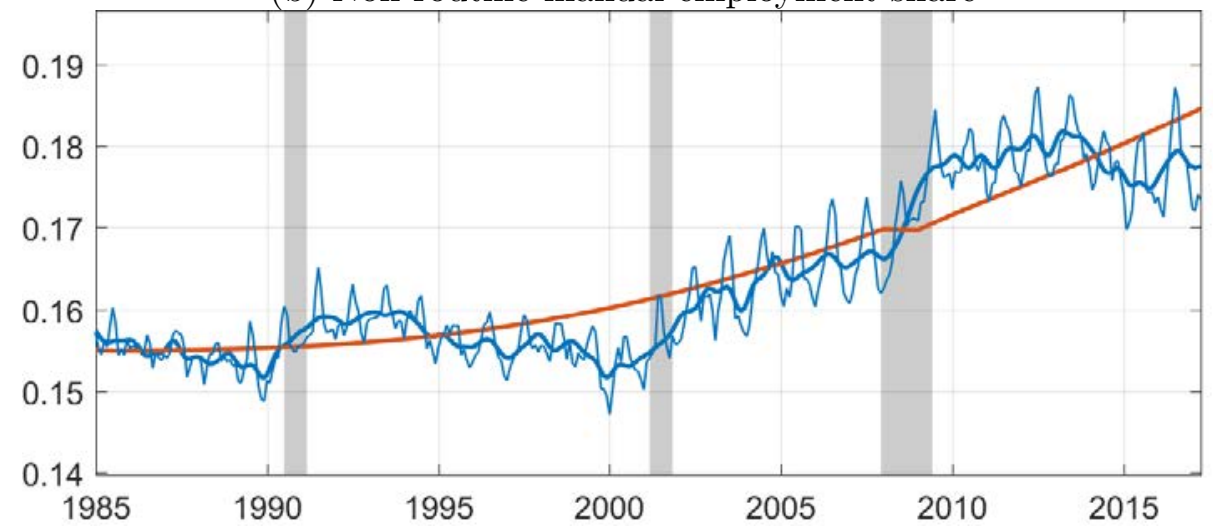

(c) Routine employment share

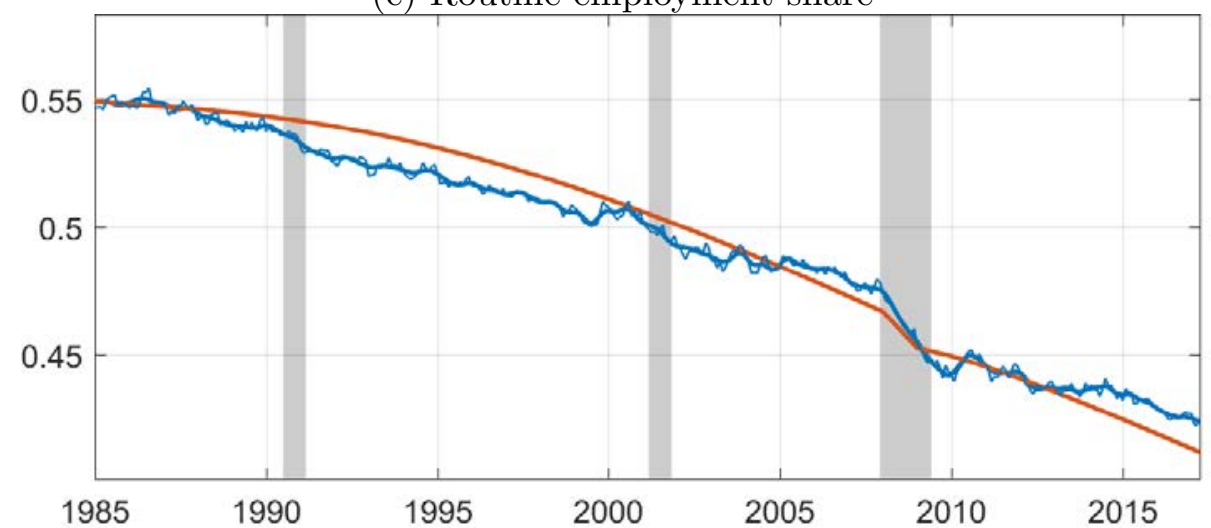

Figure 7: Employment shares by type of jobs. Definitions are from JS. Smooth blue lines show the series adjusted for seasonality with a 13-term Henderson filter (Henderson, 1916).

to the Great Recession in the data. ${ }^{25}$ The top panel of the figure shows the employment share of high-skill (model) versus non-routine cognitive (data) workers. Since the technological progress favors the high-skill-intensive technology, the corresponding employment share is gradually growing. The recession induces more active training, resulting in an upward shift of the curve. Similarly, the employment share of low-skill workers in intermediates producing firms (bottom panel) is declining and discontinuously jumps down during the downturn. Finally, low-skill services employment share (middle panel) stays almost constant for the first 15 years. Since intermediates

\footnotetext{
${ }^{25}$ The size of the shock is picked in order to match an almost $10 \%$ drop in output during the Great Recession (Fajgelbaum, Schaal, and Taschereau-Dumouchel, 2017).
} 
and manual services are strong complements, during the initial transition stage, when the intermediates output is barely changed, it is optimal not to increase the manual services output as well. Later on, low-skill employment starts to grow. ${ }^{26}$

Recent empirical evidence (e.g., JS and Hershbein and Kahn, 2016) emphasizes the acceleration of the routine employment loss during the Great Recession. Figure 8 takes a closer look at this phenomenon. In the data, the routine employment share dropped by 1.90 p.p. between 2007Q4 and 2008Q4. ${ }^{27}$ Thus, 15\% of the overall drop observed between January of 1985 and April of 2017 happened during only 1 year, or $3 \%$ of the total time span. In the model, a 2.5 standard deviation negative $z$ shock implies a drop of 1.43 p.p., or nearly $75 \%$ of what is observed in the data. In the absence of the $z$ shock, the model-implied routine employment share would have declined by only 0.61 p.p. because of the gradual transition between the steady states. The model is therefore able to replicate a substantial fraction of the routine employment loss during the Great Recession.

Routine employment share: Impact of the Great Recession

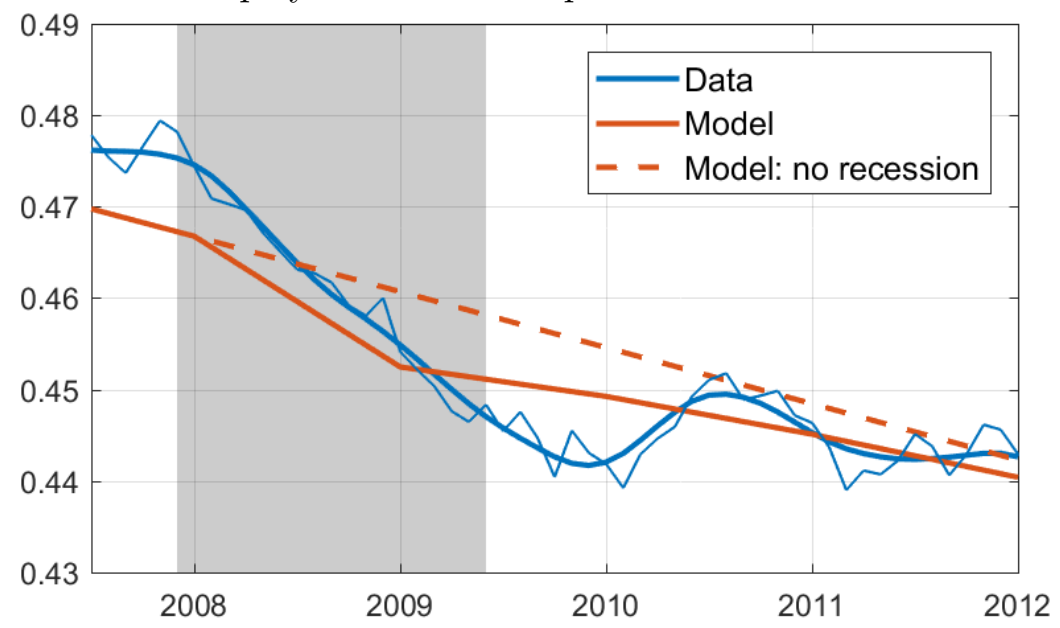

Figure 8: Routine employment share (defined as in JS) around the Great Recession. Red dashed line shows the model-implied path holding $z$ at the steady state level. The smooth blue line shows the series adjusted for seasonality with a 13-term Henderson filter (Henderson, 1916).

Overall, Figures 7 and 8 show that the model can match several important aspects of the job polarization phenomenon. First, the model is able to replicate the steady decline, since at least the start of the job polarization era, of the fraction of routine workers while, at the same time, replicating the increase in both non-routine cognitive and manual jobs. To do so, the model relies only on changes in the $A_{n}$ process and on the complementarity between intermediates and manual services. Second, the model is also able to generate the acceleration of the job polarization process

\footnotetext{
${ }^{26}$ The model does not match the increase of the non-routine manual employment share during the Great Recession. A negative TFP surprise induces reallocation of high-skill workers towards adoption and teaching. As a result, the intermediates production drops. Due to complementarity between intermediates and manual services, the marginal productivity of low-skill manual service workers declines as well and the planner therefore moves them to training.

${ }^{27}$ We consider 1 year after the start of the Great Recession, since in our model we approximate the Great Recession by 1 large negative $z$ shock.
} 
during recessions and, specifically, during the Great Recession. The counter-cyclical restructuring incentives are responsible for these rapid movements during economic downturns.

\section{Concluding remarks}

In this paper, we analyze the interaction between routine-biased technological change and business cycles. Since economic downturns are periods of low opportunity costs, they are used by firms to optimize their production technology and by workers to adjust their skill set to a changing economic environment. Restructuring incentives are enhanced during technological transitions, associated with higher than usual demand for new skills. As a result, recessions during transitions are marked by a sizable scarcity of factors in the final good production. At the same time, routinebiased technological change is accelerated, consistent with the recent empirical evidence.

The paper provides a theoretical rationale for two major features of job polarization. First, the fraction of routine workers has been declining since at least the mid 1980s, while both non-routine cognitive and non-routine manual employment shares have been growing. Second, job polarization is concentrated in recessions. In our model, a gradual technology adoption generates the trend, while large downturns speed up the transition due to counter-cyclical restructuring incentives.

The model can be extended along several important directions. First, we assume that lowskill workers can switch between routine and non-routine manual jobs without any frictions. Although costs of training for a manual services job are presumably much smaller than for a non-routine cognitive one, they are not zero. A more detailed modelling of occupation choice might help to explain an increase in the non-routine manual employment share during the Great Recession. Particularly, time to train for a manual services job is likely to make this process counter-cyclical. A model implied non-routine manual employment share should exhibit an uptick during downturns.

Furthermore, as discussed in Section 5.1.1, one could allow workers to permanently stay out of labor force, for example, by introducing a home production sector. It would be interesting to investigate, both theoretically and empirically, how routine-biased technological change and recessions along the transition path affect labor adjustments along this margin. Another potential direction would be to enrich the model with a labor-leisure choice. If the value of leisure is affected by new technologies, as suggested by Aguiar, Bils, Charles, and Hurst (2017), then the model could rationalize declining labor force participation, as well as job polarization. 


\section{References}

Acemoglu, Daron, "Changes in Unemployment and Wage Inequality: An Alternative Theory and Some Evidence", American Economic Review, 1999, 89(5), 1259-1278.

Aghion, Philippe and Gilles Saint-Paul, "Virtues of Bad Times: Interaction Between Productivity Growth and Economic Fluctuations", Macroeconomic Dynamics, 1998, 2, 322-344.

Aguiar, Mark, Marl Bils, Kerwin Kofi Charles, and Erik Hurst, "Leisure Luxuries and the Labor Supply of Young Men", Working Paper, 2017.

Aguirregabiria, Victor and Cesar Alonso-Borrego, "Occupational Structure, Technological Innovation, and Reorganization of Production", Labour Economics, 2001, 8(1), 43-73.

Andolfatto, David and Glenn M. MacDonald, "Technology Diffusion and Aggregate Dynamics", Review of Economic Dynamics, 1998, 1(2), 338-370.

Anghel, Brindusa, Sara De la Rica, and Aitor Lacuesta, "The Impact of the Great Recession on Employment Polarization in Spain", SERIEs, 2014, 5, 143-171.

Autor, David H. and David Dorn, "This Job is "Getting Old": Measuring Changes in Job Opportunities Using Occupational Age Structure", American Economic Review: Papers \&6 Proceedings, 2009, 99(2), 45-51.

Autor, David H. and David Dorn, "The Growth of Low-Skill Service Jobs and the Polarization of the US Labor Market", The American Economic Review, 2013, 103(5), 1553-1597.

Autor, David H., Frank Levy, and Richard J. Murnane, "The Skill Content of Recent Technological Change: An Empirical Exploration", Quarterly Journal of Economics, 2003, $118(4), 1279-1333$.

Barr, Andrew and Sarah Turner, "Out of Work and Into School: Labor Market Policies and College Enrollment during the Great Recession", Journal of Public Economics, 2015, 124, $63-73$.

Basu, Susanto and John G. Fernald, "Returns to Scale in U.S. Production: Estimates and Implications", Journal of Political Economy, 1997, 105(2), 249-283.

Berger, David, "Countercyclical Restructuring and Jobless Recoveries", Working Paper, 2012. 
Bernard, Andrew B., Jonathan Eaton, J. Bradford Jensen, and Samuel Kortum, "Plants and Productivity in International Trade", The American Economic Review, 2003, $93(4), 1268-1290$.

Bresnahan, Timothy F. and Manuel Trajtenberg, "General Purpose Technologies 'Engines of Growth'?", Journal of Econometrics, 1995, 65, 83-108.

Brynjolfsson, Erik, "The Productivity Paradox of Information Technology", Communications of the ACM, 1993, 36(12), 66-77.

Brynjolfsson, Erik and Lorin M. Hitt, "Computing Productivity: Firm-Level Evidence", Review of Economics and Statistics, 2003, 85(4), 793-808.

Brynjolfsson, Erik, Thomas W. Malone, Vijay Gurbaxani, and Ajit Kambil, "Does Information Technology Lead to Smaller Firms?", Management Science, 1994, 40(12), 16281644.

Brynjolfsson, Erik and Andrew McAfee, Race Against The Machine: How The Digital Revolution Is Accelerating Innovation, Driving Productivity, and Irreversibly Transforming Employment and The Economy, Brynjolfsson and McAfee .

Buera, Francisco J. and Joseph P. Kaboski, "Can Traditional Theories of Structural Change Fit the Data?", Journal of European Economic Association, 2009, 7(2/3), 469-477.

Buera, Francisco J., Joseph P. Kaboski, and Richard Rogerson, "Skill Biased Structural Change", Working Paper, 2015.

Caballero, Ricardo J. and Eduardo M. R. A. Engel, "Explaining Investment Dynamics in U.S. Manufacturing: A Generalized (S,s) Approach", Econometrica, 1999, 67(4), 783-826.

Caballero, Ricardo J. and Mohamad L. Hammour, "The Cleansing Effect of Recessions", American Economic Review, 1994, 84 (5), 1350-1368.

Charles, Kerwin Kofi, Erik Hurst, and Matthew Notowidigdo, "Housing Booms and Busts, Labor Market Opportunities, and College Attendence”, Working Paper, 2015.

Cooley, Thomas F. and Edward C. Prescott, "Economic Growth and Business Cycles", in "Frontiers of Business Cycle Research", 1995.

Cooper, Russell and John Haltiwanger, "The Aggregate Implications of Machine Replacement: Theory and Evidence", American Economic Review, 1993, 83(3), 360-382. 
Cortes, Guido Matias, Nir Jaimovich, Christopher J. Nekarda, and Henry E. Siu, "The Micro and Macro of Disappearing Routine Jobs: A Flows Approach", Working Paper, 2014.

Cortes, Guido Matias, Nir Jaimovich, and Henry E. Siu, "Disappearing Routine Jobs: Who, How, and Why?", Working Paper, 2016.

Crafts, Nicholas, "Steam as a General Purpose Technology: A Growth Accounting", The Economic Journal, 2004, 114(495), 338-351.

David, Paul A., "The Dynamo and the Computer: An Historical Perspective on the Modern Productivity Paradox", The American Economic Review: Papers and Proceedings, 1990, 80(2), $355-361$.

DeJong, David N. and Beth F. Ingram, "The Cyclical Behavior of Skill Acquisition", Review of Economic Dynamics, 2001, 4, 536-561.

Dellas, Harris and Plutarchos Sakellaris, "On the Cyclicality of Schooling: Theory and Evidence", Oxford Economic Papers, 2003, 55(1), 148-172.

Eden, Maya and Paul Gaggl, "On the Welfare Implications of Automation", Working Paper, 2016.

Fajgelbaum, Pablo D., Edouard Schaal, and Mathieu Taschereau-Dumouchel, "Uncertainty Traps", Quarterly Journal of Economics, 2017, 132(4), 1641-1692.

Goldin, Claudia and Lawrence F. Katz, "The Origins of Technology-Skill Complementarity", The Quarterly Journal of Economics, 1998, 113(3), 693-732.

Goos, Maarten and Alan Manning, "Lousy and Lovely Jobs: The Rising Polarization of Work in Britain", The Review of Economics and Statistics, 2007, 89(1), 118-133.

Goos, Maarten, Alan Manning, and Anna Salomons, "Explaining Job Polarization: Routine-Biased Technological Change and Offshoring", The American Economic Review, 2014, $104(8), 2509-2526$.

Greenwood, Jeremy and Mehmet Yorukoglu, "1974”, Carnegie-Rochester Conference Series on Public Policy, 1997, 46, 49-95.

Griliches, Zvi, "Capital-Skill Complementarity", The Review of Economics and Statistics, 1969, 51(4), 465-468. 
Grossman, Gene M. and Elhanan Helpman, "Quality Ladders and Product Cycles", The Quarterly Journal of Economics, 1991, 106(2), 557-586.

Hall, Robert E., "Recessions as Reorganizations", NBER Macro Annual Conference, 1991.

Heckman, James J., "A Life-Cycle Model of Earnings, Learning, and Consumption", Journal of Political Economy, 1976, 84(4), S11-S44.

Heckman, James J, Lance Lochner, and Christopher Taber, "Explaining Rising Wage Inequality: Explorations with a Dynamic General Equilibrium Model of Labor Earnings with Heterogeneous Agents", Review of Economic Dynamics, 1998, 1, 1-58.

Helpman, Elhanan, General Purpose Technologies and Economic Growth, MIT Press 1998.

Henderson, Robert, "Note on Graduation by Adjusted Average", Transactions of the Actuarial Society of America, 1916, 17, 43-48.

Herrendorf, Berthold, Richard Rogerson, and Akos Valentinyi, "Growth and Structural Transformation", Working Paper, 2013.

Hershbein, Brad and Lisa B. Kahn, "Do Recessions Accelerate Routine-Biased Technological Change?", Working Paper, 2016.

Hsieh, Chang-Tai and Peter J. Klenow, "The Life-Cycle of Plants in India and Mexico", The Quarterly Journal of Economics, 2014, 129(3), 1035-1084.

Jaimovich, Nir and Henry E. Siu, "Job Polarization and Jobless Recoveries", Working Paper, 2015.

Jovanovic, Boyan and Glenn M. Macdonald, "Competitive Diffusion", Journal of Political Economy, 1994, 102(1), 24-52.

Jovanovic, Boyan and Peter L. Rousseau, "General Purpose Technologies", in "Handbook of Economic Growth", 2005.

Koenders, Kathryn and Richard Rogerson, "Organizational Dynamics Over the Business Cycle: A View on Jobless Recoveries", Federal Reserve Bank of St Louis Review, 2005, 87(4), 555-579.

Krusell, Per, Lee E. Ohanian, Jose-Victor Rios-Rull, and Giovanni L. Violante, "Capital-Skill Complementarity and Inequality: A Macroeconomic Analysis", Econometrica, 2000, 68(5), 1029-1053. 
Mincer, Jacob and Haim Ofek, "Interrupted Work Careers: Depreciation and Restoration of Human Capital", The Journal of Human Resources, 1982, 17(1), 3-24.

Nelson, Richard R. and Edmund S. Phelps, "Investment in Humans, Technological Diffusion, and Economic Growth", The American Economic Review, 1966, 56(1), 69-75.

Perli, Roberto and Plutarchos Sakellaris, "Human Capital Formation and Business Cycle Persistence", Journal of Monetary Economics, 1998, 42(1), 67-92.

Romer, Paul M., "Endogenous Technological Change", Journal of Political Economy, 1990, 98(5), S71-S102.

Schumpeter, Joseph A., Capitalism, Socialism, and Democracy, New York: Harper \& Row 1934.

van Rens, Thijs, "Organizational Capital and Employment Fluctuations", Working Paper, 2004.

Ward, Colin, "Is the IT Revolution Over? An Asset Pricing View", Working Paper, 2015.

Zhang, Miao Ben, "Labor-Technology Substitution: Implications for Asset Pricing", Working Paper, 2015. 


\section{Appendix}

\section{A Industrial robots}

Figure A1 shows the worldwide shipment of industrial robots. After a temporary drop in 2009, the series recovered quickly and has been growing at a faster rate afterwards. The model interprets this data as an increase in technology adoption in the aftermath of the recession.

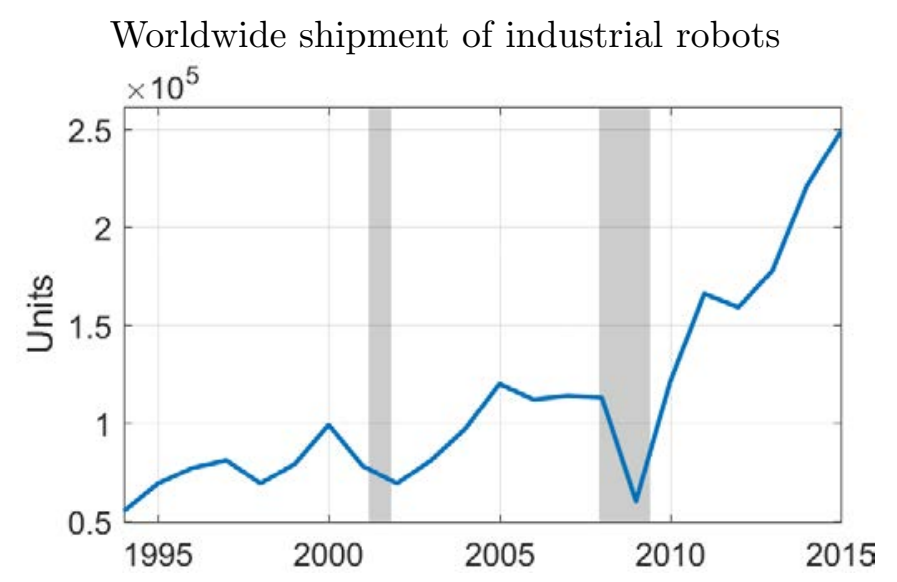

Figure A1: Data source: International Federation of Robotics.

\section{B Substitutability between new and old technologies}

In the main text, we assume that the new and old technologies produce imperfectly substitutable varieties, with elasticity of substitution of $\frac{1}{1-\theta}=4$. In this Appendix, we consider the case of perfect substitutability between the varieties so that $\theta=1$. If we kept all other parameters besides $\theta$ at the same values, the transition between the technologies would be much more concentrated in time. When new and old intermediates are perfect substitutes, it is optimal for firms to adopt the new technology only when its productivity $A_{n}$ becomes very close to $A_{o}$. On the other hand, when $A_{n}$ grows slightly above $A_{o}$, old firms massively adopt the new technology. In order to generate gradual transition paths, we have to either significantly increase the adoption costs or to reparametrize the $A_{n}(t)$ process. Since the model already features a nontrivial adoption lag of several years, we take the second approach.

We set $A_{n}^{0}=1.0015$ and $\bar{A}_{n}=1.0184$ and keep $T_{\text {finish }}-T_{\text {start }}=75$ years. The left column of Figure A2 depicts the employment shares under this parametrization. The model can still match the non-routine cognitive and routine employment shares, it now fails to deliver a pronounced 
Only $A_{n}$ growing

(a1) Non-routine cognitive employment share

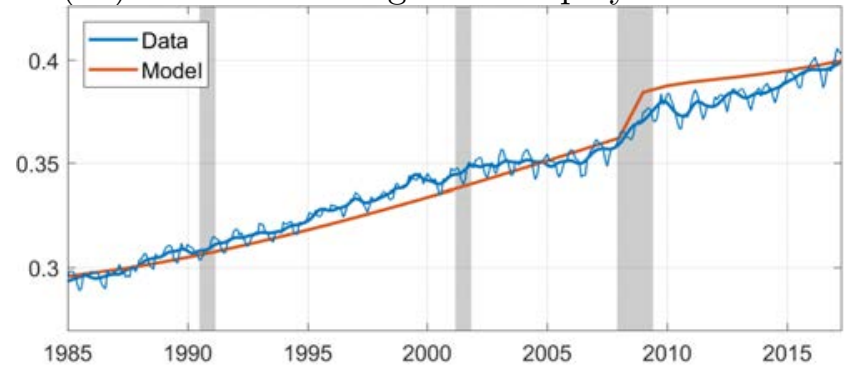

(b1) Non-routine manual employment share

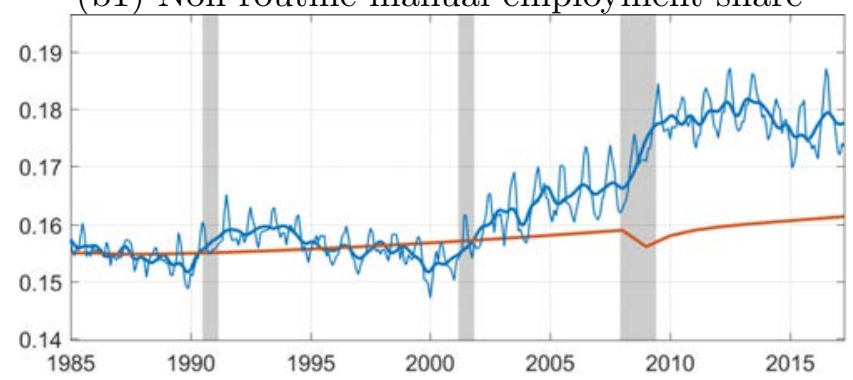

(c1) Routine employment share

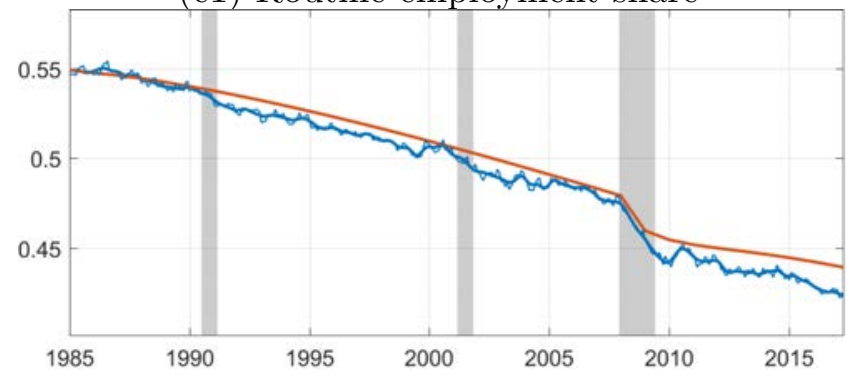

$A_{n}$ and $A_{o}$ growing

(a2) Non-routine cognitive employment share

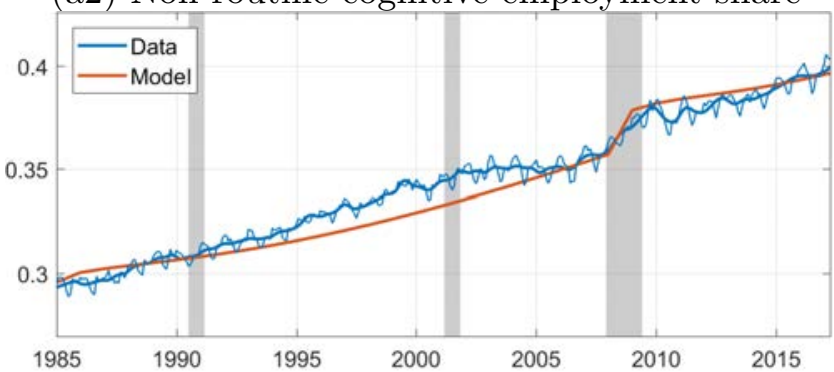

(b2) Non-routine manual employment share

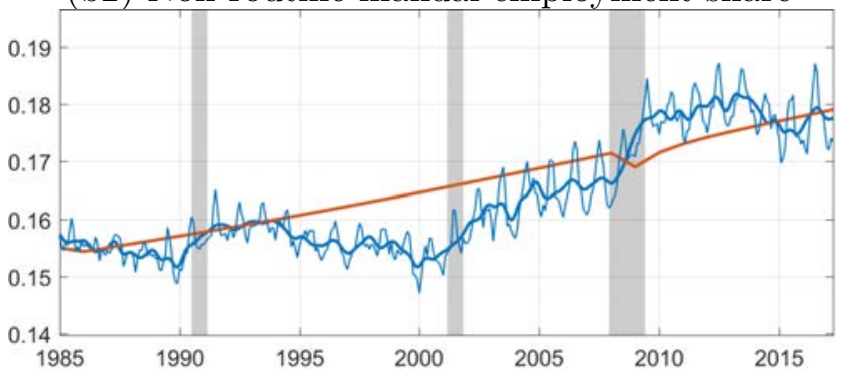

(c2) Routine employment share

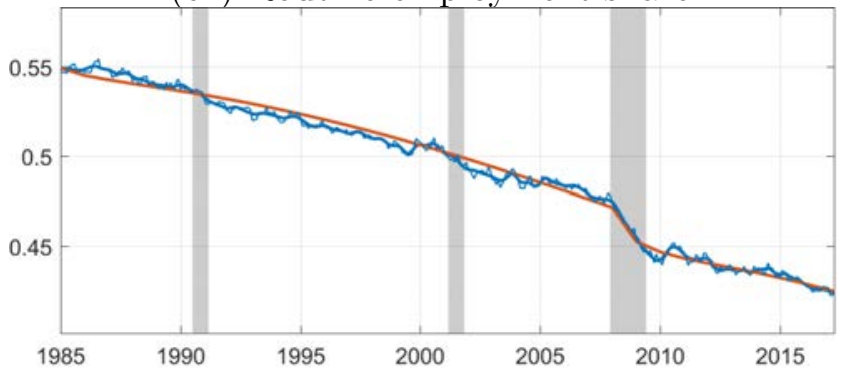

Figure A2: Employment shares by type of jobs: $\theta=1$. The left column shows the series when only $A_{n}$ grows. The right column shows the series when both $A_{n}$ and $A_{o}$ grow, with the former one at a faster pace.

increase in the non-routine manual employment share however. In the main text, employment in manual services grows since a change in $A_{n}$ leads to a significant boost in the production of intermediates. Since the two inputs are strong complements in the final consumption bundle, low-skill labor optimally flows to manual services. When $\theta=1$, only a small increment in $A_{n}$ is required to initiate the transition. Intermediates output barely changes. As a result, employment in manual services goes up only marginally.

In order to generate an increase in the non-routine manual employment share, the model can be extended by assuming that the productivity of the old technology also grows, although at a slower pace then the productivity of the new technology. To do so we assume that there is a common term $A_{i}(t)$ to both processes so that the productivity of the old and new technology are $A_{i}(t)$ and $A_{i}(t) A_{n}(t)$. We keep the $A_{n}(t)$ process the same as before and parametrize the $A_{i}(t)$ process in 
the same spirit,

$$
A_{i}(t)= \begin{cases}1, & t<T_{\text {start }}, \\ 1+\left(\bar{A}_{i}-1\right) \frac{1-\exp \left(\frac{T_{\text {start }}-t}{T_{\text {finish }}-T_{\text {start }}}\right)}{1-\exp (-1)}, & t \in\left[T_{\text {start }}, T_{\text {finish }}\right] \\ \bar{A}_{i}, & t>T_{\text {finish }} .\end{cases}
$$

We set $\bar{A}_{i}=1.23$.

The employment shares are depicted in the right column of Figure A2. Not surprisingly, now the model can generate an increase in the non-routine manual employment share. The dynamics of the non-routine cognitive and routine employment shares move downwards slightly. When overall productivity of intermediates $A_{i}$ goes up, low-skill labor is reallocated towards manual services. Fewer low-skill workers are employed in intermediates, which pushes down the routine employment share. Since low and high-skill labor are complements in the intermediates production, it is optimal to decrease the number of high-skill workers as well. As a result, the non-routine cognitive employment share moves downwards.

(a) Productivity, $z$

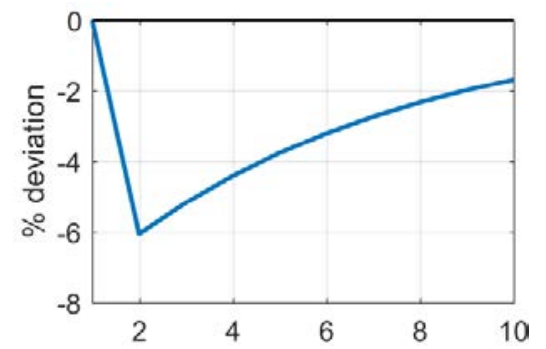

(d) L-S in training, $U_{s}$

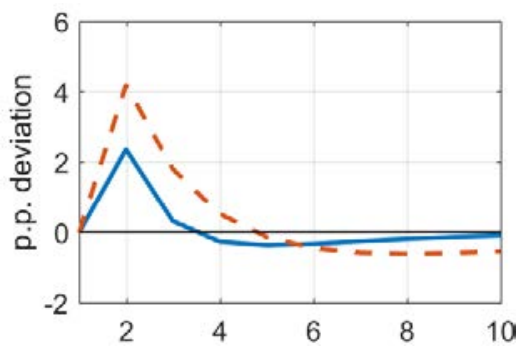

(b) Output, $Y_{f}$

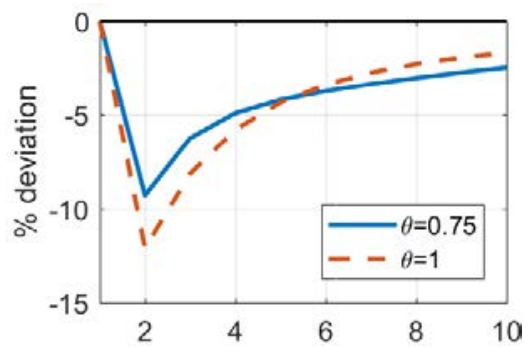

(e) H-S in adoption, $H_{a}$

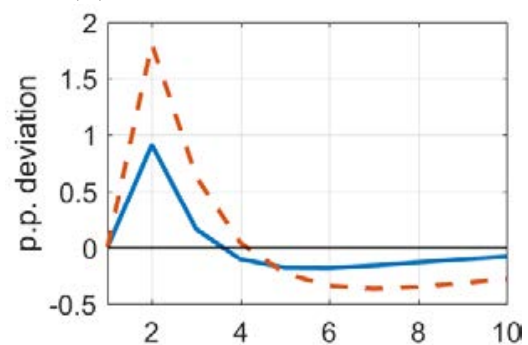

(c) Production empl, $H_{p}+U_{p}$

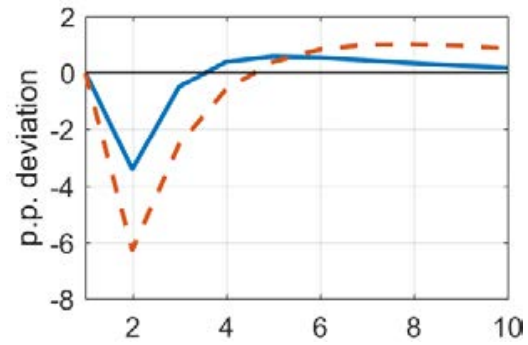

(f) New firms, $m_{n}$



Figure A3: IRFs to a negative $z$ shock. Graphs are plotted relative to no $z$ shock scenarios.

The interaction of the technological transition with recessions does not change qualitatively when $\theta=1$. Figure A3 shows the impulse response functions to the same $z$ shock for $\theta=0.75$ (benchmark) and $\theta=1$. With perfect substitutability, downturns induce more technology adoption. When $\theta=1$, new and old firms produce the same good and profits of old firms does not depend much on the mass of producing old firms $m_{o}$. In case of imperfect substitutability, old firms produce their own variety. When some of them halt their production and try to adopt the new 
technology, profits of the remaining old firms increase substantially. Accelerated adoption for $\theta=1$ requires additional high-skill workers and capital. Since high and low-skill labor are complements in the production process, more low-skill workers choose to train. As a result, output drops by $12 \%$ on impact (with $\theta=0.75$ the drop is about $10 \%$ for the same shock).

\section{Expectations and business cycles}

In the main text, we analyze the impact of unanticipated $z$ shocks on the economy. Since reorganization is counter-cyclical in our model, the anticipation of recessions can affect the agents' behavior in an important way. Being aware of a possible downturn in the future, old firms are likely to postpone technology adoption and low-skill workers to defer training until bad times.

In order to investigate the importance of this anticipation channel, we do the following exercise. Assume that in 2003, 5 years before the Great Recession, all agents in the economy learn that a regular recession will happen in 2008. Particularly, $z$ is going to drop by 0.55 standard deviations with certainty, which will lead to a $2 \%$ drop in output, an average GDP decline for postwar US recessions. In 2008, recession indeed happens; however, it is much worse than expected ( $z$ drops by 2.5 standard deviations instead).

(a) Productivity, $z$

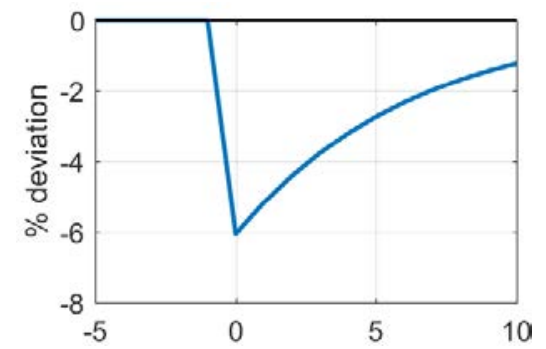

(d) L-S in training, $U_{s}$

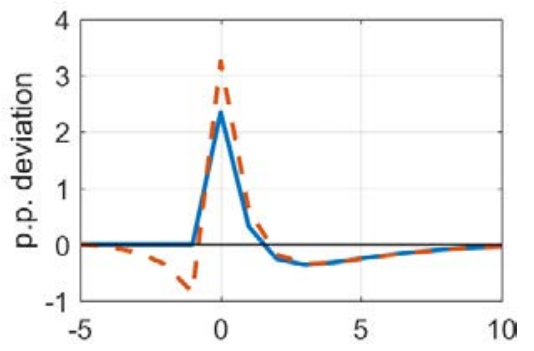

(b) Output, $Y_{f}$

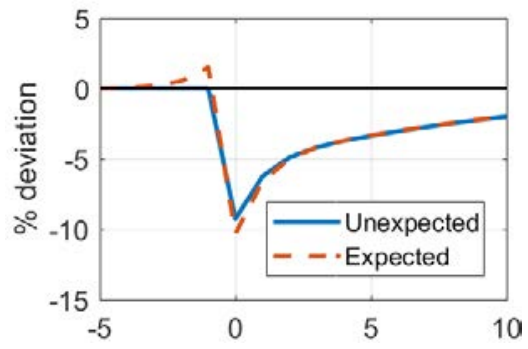

(e) $\mathrm{H}-\mathrm{S}$ in adoption, $H_{a}$

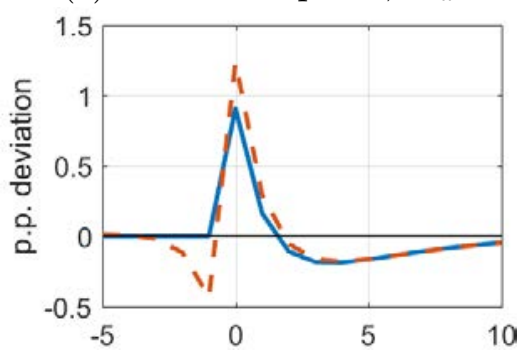

(c) Production empl, $H_{p}+U_{p}$

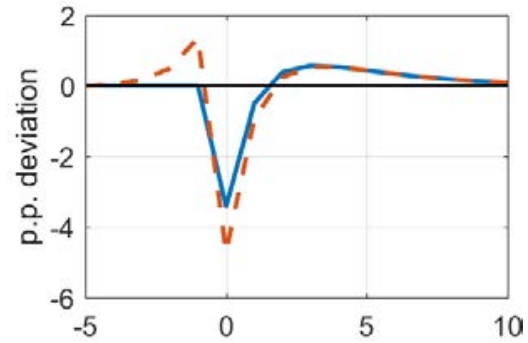

(f) New firms, $m_{n}$

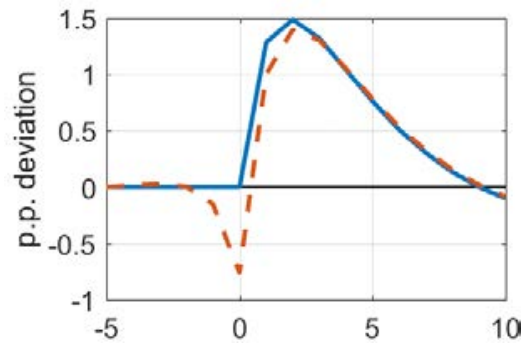

Figure A4: IRFs to a negative $z$ shock. Graphs are plotted relative to no $z$ shock scenarios. In case of expected shocks, in period -5 the agents learn that at period 0 a regular recession is going to happen

Figure A4 compares the results of this exercise with the benchmark case when shocks are completely unanticipated. In response to a negative news shock, the economy experiences a mild 
boom. $^{1}$ A future recession incentivizes old firms to postpone technology adoption until then. Consistently, low-skill workers decrease school attainment. Reorganization needs are therefore elevated by the time of a negative $z$ surprise. When a worse than expected recession happens, training and adoption go up to a larger extent than in the benchmark case. Output declines more.

Anticipation of recessions amplifies counter-criticality of training and technology adoption. However, the results of our exercise suggest that this channel plays a secondary role. Moreover, we make an extreme assumption that all agents in the economy know about a future negative $z$ shock with certainty. The exercise is therefore likely to provide an upper bound on the strength of the anticipation effect.

\section{Business cycles in the new steady state}

(a) Productivity, $z$

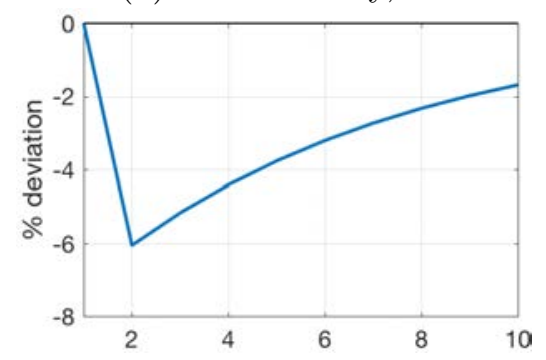

(d) L-S in training, $U_{s}$

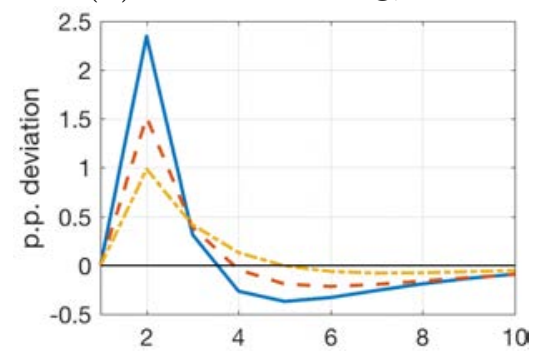

(b) Output, $Y_{f}$

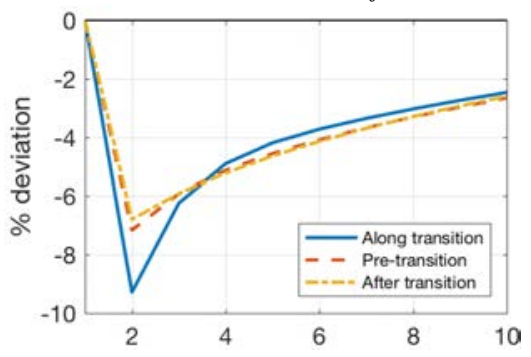

(e) H-S in adoption, $H_{a}$

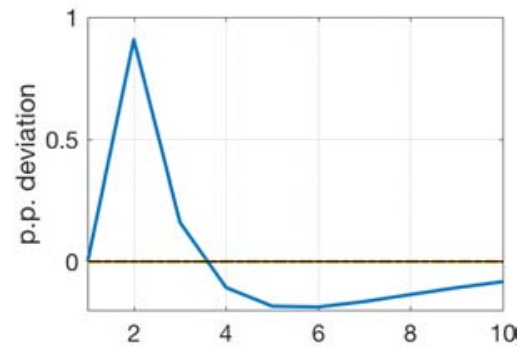

(c) Production empl, $H_{p}+U_{p}$

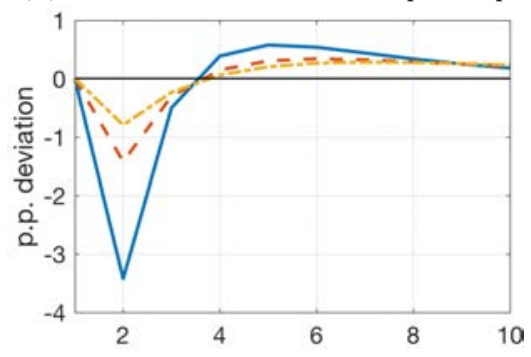

(f) New firms, $m_{n}$

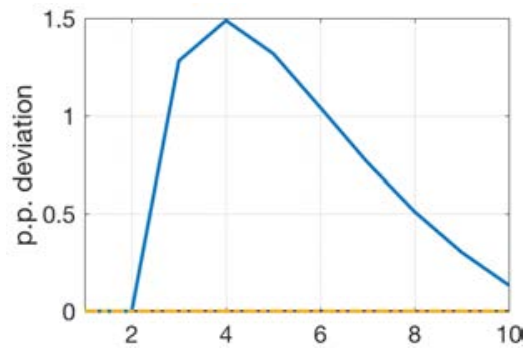

Figure A5: IRFs to a negative $z$ shock. Graphs are plotted relative to no $z$ shock scenarios.

In the model, the arrival of the new technology is associated with a change in the production function. This can affect the economy's responses to business cycle shocks by itself. In this Appendix, we compare the impulse responses to the same 2.5 standard deviation negative $z$ shock in three scenarios. In the first case, the economy is the initial steady state; in the second case, the economy is in transition; in the third case, the economy is in the new steady state. ${ }^{2}$ The results are given in Figure A5. When the economy is in a steady state (either new or old), the

\footnotetext{
${ }^{1}$ As in Jaimovich and Rebelo (2009), investment adjustment costs might overturn this result and generate a recession in response to a negative news shock.

${ }^{2}$ For the latter case, we assume that the technology is fully absorbed, so the masses of new and old firms are constant.
} 
only amplification mechanism is the reallocation of labor from production to training. It turns out that this channel is weaker in the new steady state than in the old one. The economy in transition is marked by an other reallocation dimension (towards the adoption process), which generates a substantial additional drop in the final good production.

\section{E Training-adoption complementarity}

In the model, the training of the workers and the adoption of the new technology tend to happen simultaneously. Besides both being attractive in periods of low opportunity costs, and hence counter-cyclical, these activities might comove for two additional reasons. First, technology adoption leads to elevated demand for high skill since the new technology is skill-intensive, while training increases the supply of high-skill workers. Second, the adoption process is intensive in high-skill labor, while training mainly requires students, i.e. low-skill workers. Since the two types of labor are complements in the intermediates production, it is optimal to reallocate low-skill workers to training and high-skill workers to adoption synchronously.

(a) Productivity, $z$

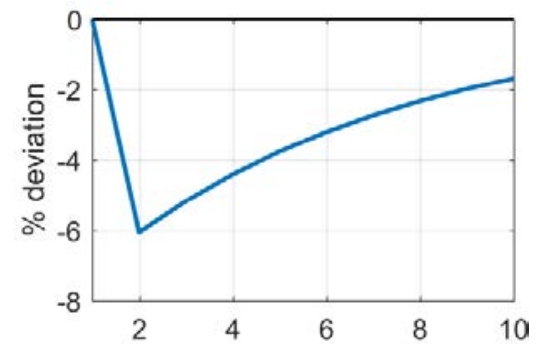

(d) L-S in training, $U_{s}$

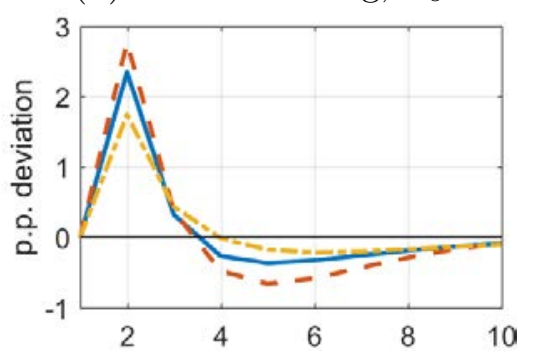

(b) Output, $Y_{f}$

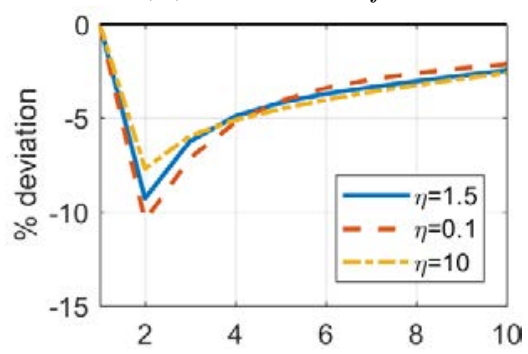

(e) $\mathrm{H}-\mathrm{S}$ in adoption, $H_{a}$

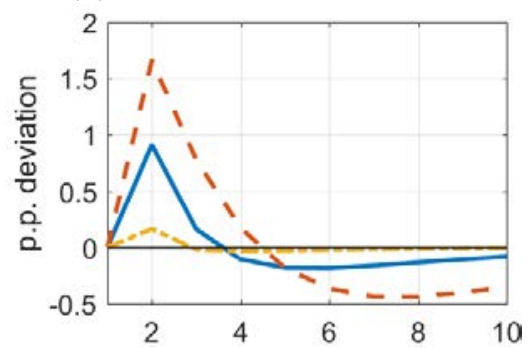

(c) Production empl, $H_{p}+U_{p}$

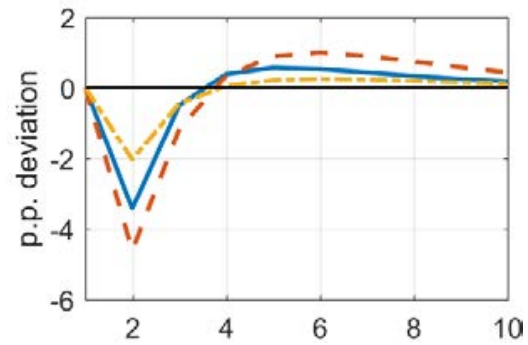

(f) New firms, $m_{n}$

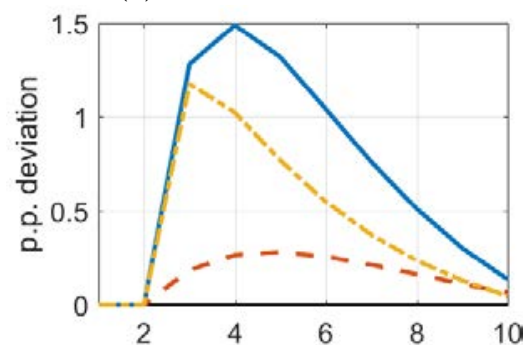

Figure A6: IRFs to a negative $z$ shock. Graphs are plotted relative to no $z$ shock scenarios.

In order to investigate the quantitative importance of these two mechanisms, we vary the ease of adoption of the technology (parameter $\eta$ ). ${ }^{3}$ The results, shown in Figure A6, suggest that the second channel plays a dominant role. For a small $\eta=0.1$, technological change requires a lot of resources. In recessions, many high-skill workers are needed to satisfy the elevated demand by adopting firms. For such a low $\eta$, the mass of new firms responds only slightly to the shock.

\footnotetext{
${ }^{3}$ For all three values of $\eta$ we reparametrize the $A_{n}(t)$ process to match the dynamics of the employment shares.
} 
Nevertheless, the reallocation of low-skill labor towards training is substantial. On the contrary, when $\eta=10$, adoption requires only a few high-skill workers. As a result, the mass of new firms increases substantially in this case. However, investment in training is smaller than for $\eta=1.5$ and $\eta=10$.

We conclude that two main forces contribute to the additional amplification of negative $z$ shocks during the technological transition. Being counter-cyclical, adoption induces reallocation of highskill labor. This further depresses the marginal productivity of low-skill workers in production, given that the two types of labor complement each other there. Low-skill labor therefore transitions into training.

\section{F Different output measures}

(a) $Y_{f}$

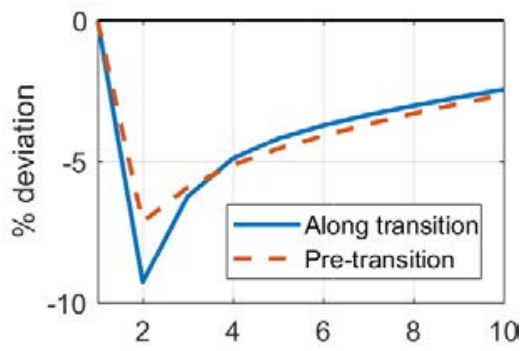

(b) $Y_{a d j, 1}$

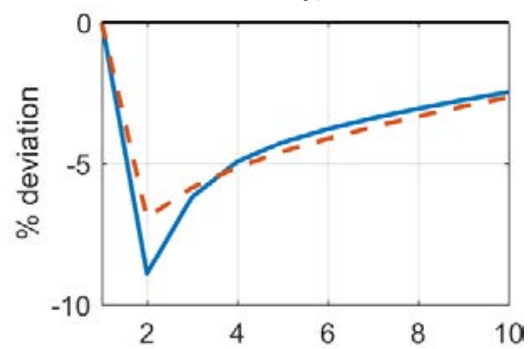

(c) $Y_{a d j, 2}$

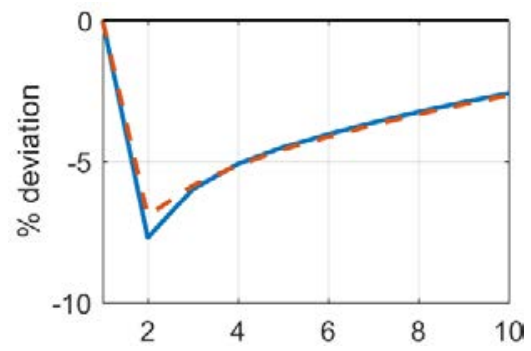

Figure A7: Impact of a negative $z$ shock on output, measured in three different ways.

Our main measure of output is the the total production of the final good product $Y_{f}$. In this Appendix, we adjust this measure by taking into account the elevated reorganization and training costs due to the reallocation of high-skill labor and capital towards training and adoption,

$$
\begin{gathered}
Y_{a d j, 1}=Y_{f}+w_{h} H_{s}+r K_{s}, \\
Y_{a d j, 2}=Y_{f}+w_{h}\left(H_{a}+H_{s}\right)+r\left(K_{a}+K_{s}\right),
\end{gathered}
$$

and repeat the same exercise as in Section 5.1.2. ${ }^{4}$ The results are given in Figure A7.

The same $z$ shock always leads to a larger drop in aggregate output for the economy in transition, even if the output measure is adjusted for adoption and training. The remaining difference is due to two channels. First, adoption requires not only high-skill labor and capital but also the mass of

\footnotetext{
${ }^{4}$ It is not clear whether output adjusted in this way makes the model closer to reality. In the data investment in human and organizational capital might be largely mismeasured, as pointed out by, for example, Brynjolfsson and McAfee (2014).
} 
firms itself as a production factor, so ideally output measures should be adjusted for that as well. Second, training adjustment do not account for elevated opportunity costs of low-skill students. 


\section{References: Appendix}

Brynjolfsson, Erik and Andrew McAfee, The Second Machine Age: Work, Progress, and Prosperity in a Time of Brilliant Technologies, WW Norton \& Company 2014.

Jaimovich, Nir and Sergio Rebelo, "Can News about the Future Drive the Business Cycle?", The American Economic Review, 2009, 99(4), 1097-1118. 